\title{
Mechanism of Oxygen Evolution Catalyzed by Cobalt Oxyhydroxide: Cobalt Superoxide Species as a Key Intermediate and Dioxygen Re- lease as a Rate-Determining Step
}

\author{
Aliki Moysiadou, ${ }^{\dagger, \ddagger}$ Seunghwa Lee, ${ }^{\dagger, \ddagger}$ Chia-Shuo Hsu, ${ }^{\S}$ Hao Ming Chen, ${ }^{\S}$ Xile Hu ${ }^{\dagger, *}$ \\ ${ }^{\dagger}$ Laboratory of Inorganic Synthesis and Catalysis, Institute of Chemical Sciences and Engineering, École Polytech- \\ nique Fédérale de Lausanne (EPFL), ISIC-LSCI, 1015 Lausanne, Switzerland. \\ $\S$ Department of Chemistry, National Taiwan University, Taipei 10617, Taiwan.
}

\begin{abstract}
The oxygen evolution reaction (OER) is the performance-limiting half reaction of water splitting, which can be used to produce hydrogen fuel using renewable energies. Whereas a number of transition metal oxide and oxyhydroxide have been developed as promising OER catalysts in alkaline medium, the mechanisms of OER on these catalysts are not well understood. Here we combine electrochemical and in situ spectroscopic methods, particularly operando X-ray absorption and Raman spectroscopy, to study the mechanism of OER on cobalt oxyhydroxide ( $\mathrm{CoOOH})$, an archetypical unary OER catalyst. We find the dominating resting state of the catalyst as a $\mathrm{Co}(\mathrm{IV})$ species $\mathrm{CoO}_{2}$. Through oxygen isotope exchange experiments, we discover a cobalt superoxide species as an active intermediate in the OER. This intermediate is formed concurrently to the oxidation of $\mathrm{CoOOH}$ to $\mathrm{CoO}_{2}$. Combing spectroscopic and electrokinetic data, we identify the rate-determining step of the OER as the release of dioxygen from the superoxide intermediate. The work provides important experimental fingerprints and new mechanistic perspectives for OER catalysts.
\end{abstract}

\section{INTRODUCTION}

The oxygen evolution reaction (OER) is the oxidative halfreaction of the water-splitting reaction, which can be used to produce hydrogen using renewable energies. ${ }^{1-3}$ Many transition metal oxides and oxyhydroxides containing $\mathrm{Co}$, $\mathrm{Fe}$, and Ni have been developed for OER in alkaline medium, ${ }^{4-6}$ where their activity rivals that of precious metal oxides such as $\mathrm{IrO}_{x}$ and $\mathrm{RuO}_{x}$. Despite the progress in catalyst development, the mechanistic understanding of OER catalyzed by these oxides and oxyhydroxides remains incomplete. Hydroxide attack of a metal oxo moiety, ${ }^{6-9}$ and to a less degree, the radical coupling of two metal oxo units, ${ }^{10,11}$ are typically assumed to be the rate-determining step of OER. However, spectroscopic evidence of metal oxo intermediates is scarce. ${ }^{12}$ Moreover, the proposed mechanisms are rarely supported by kinetic data. ${ }^{10,13,14}$ Here we report spectroscopic and electrokinetic evidence for the mechanism of OER catalyzed by Co oxyhydroxide $(\mathrm{CoOOH})$, which involves a superoxide species as an intermediate and oxygen release as the rate-determining step. These mechanistic features are unusual not only for Cobased catalyst, but also metal oxide and oxyhydroxide catalysts in general. Their experimental identification challenges the common assumptions of the field and enhances the general mechanistic understanding of OER.

We chose to study amorphous $\mathrm{CoOOH}$ because it exhibits one of the highest activities for a unary metal oxide or oxyhydroxide. 9 As Co is the only metal in the catalyst, it is the unequivocal active site. This scenario facilitates the mechanistic study. As a contrast, the active site of mixed metal oxides and oxyhydroxides containing two or more potentially active metals such as $\mathrm{Fe}, \mathrm{Co}$, and $\mathrm{Ni}$ can be difficult to assign, making mechanistic studies difficult. In this context, our study of $\mathrm{CoOOH}$ provides an important reference for the elucidation of the mechanisms of OER catalyzed by mixed metal oxides containing Co.

2. RESULTS

2.1 Preparation and characterization of cobalt oxyhydroxide. Amorphous cobalt oxyhydroxide $(\mathrm{CoOOH})$ was prepared by anodic electrodeposition onto a nanostructured Au substrate following a previously reported procedure. .5-17 $^{-17}$ morphology and thickness of the substrate and film were investigated by Scanning Electron Microscopy (SEM). SEM images of a smooth Au and a typical nanostructured Au are shown in Figure Sia and Figures Sib, $c$ respectively. The electrochemical surface area (ECSA) of a smooth $\mathrm{Au}$ increased by nearly two times after the roughening procedure resulting in a typical roughness factor of $\sim 9.5$ (Figure $\mathrm{S}_{2}$, Table $\mathrm{S}_{1}$ ) in accordance with previous reports. ${ }^{18}$ To estimate the thickness of a film on the roughened $\mathrm{Au}, \mathrm{CoOOH}$ was electrochemically deposited on a flat FTO glass $\left(0.196 \mathrm{~cm}^{2}\right)$ applying an equal anodic charge ( $9171 \mu \mathrm{C}$ per geometrical surface area). The thickness of the film on the FTO glass was around $\mathbf{2 0 - 2 4} \mathrm{nm}$ (Figures $\mathrm{S} 1 \mathrm{~d}$ and e), which corresponded to an estimated thickness of 2.0-2.5 $\mathrm{nm}$ on the nanostructured Au (roughness factor, RF $\sim 9.50$, Table $\mathrm{S1}$ ). From double-layer capacitance measurements by cyclic voltammetry (CV) shown in Figures $\mathrm{S}_{3} \mathrm{a}, \mathrm{b}$, the roughness factor of $\mathrm{CoOOH}$ was $\sim 63 \pm 15$, which was similar to the value obtained by fitting the electrochemical 
impedance spectroscopy (EIS) data ( 70 \pm 15 , Table S2). The real active surface areas might differ from ECSAs due to the intrinsic limitations of the methods based on capacitances such as permeability and poor conductivity (for a discussion, see SI). ${ }^{19,20}$

The chemical composition of the films was analyzed by XPS (Figure S4, SI). Due to spin-orbit splitting, the highresolution Co $2 \mathrm{p}$ spectrum comprises two main peaks attributed to $\mathrm{Co}_{2} \mathrm{p}_{1 / 2}$ and $\mathrm{Co}_{2} \mathrm{P}_{3 / 2}$, respectively. The binding energy of the Co $2 \mathrm{p}_{3 / 2}$ peak is about $780.4 \mathrm{eV}$. Because $\mathrm{Co}(\mathrm{II})$ and $\mathrm{Co}(\mathrm{III})$ compounds have similar binding energies $^{21,22}$, the spectrum cannot be used to assign the oxidation state of Co. The high resolution $\mathrm{O}$ 1s XPS spectrum is fitted with three separate peaks: a main peak at $531.3 \mathrm{eV}$ assigned to oxygen atoms of surface hydroxyl groups $\left(\mathrm{OH}^{-}\right.$ ), a second peak at $529.8 \mathrm{eV}$ related to lattice oxygen $\left(\mathrm{O}^{2-}\right)$, and a third one ca. $533 \mathrm{eV}$ associated with adsorbed water molecules. ${ }^{8,21,22}$ The chemical composition of films after a short-term galvanostatic electrolysis (at $5 \mathrm{~mA} \mathrm{~cm}{ }^{-2}$ for three hours) is depicted in Figure S4c,d. The high-resolution Co 2p spectrum shows no significant difference from the as-prepared catalyst. A new peak appeared at about $530.8 \mathrm{eV}$ in the high-resolution $\mathrm{O}$ is spectrum, which was previously attributed to peroxo-like species $\left(\mathrm{O}_{2}{ }^{2-}\right) .{ }^{23,24}$

Figure 1a depicts a typical voltammogram of $\mathrm{CoOOH}$ film on carbon cloth recorded in o.1 $\mathrm{M}$ Fe-free $\mathrm{KOH}$ at a scan rate of $100 \mathrm{mV} \mathrm{s}^{-1}$. We refer all potentials towards the RHE scale unless differently stated. The two pairs of redox events $\left(E_{\mathrm{pa}}, E_{\mathrm{pc}}\right.$, and $\left.E_{\mathrm{pa}}, E_{\mathrm{pc}}^{\prime}\right)$ observed were tentatively attributed to Co-related reactions according to literature (equations 1 and 2, respectively).25-29 In the forward scan, the $\mathrm{Co}(\mathrm{II})$ to $\mathrm{Co}(\mathrm{III})$ oxidation peak appeared at ca. $1.215 \pm 0.005 \mathrm{~V}\left(E_{\mathrm{pa}}\right)$. A second oxidation wave, assigned to the $\mathrm{Co}(\mathrm{III}) / \mathrm{Co}(\mathrm{IV})$ redox couple, peaked at ca. $1.500 \pm 0.005$ $\mathrm{V}\left(E_{\mathrm{pa}}\right)$.

$\mathrm{Co}(\mathrm{OH})_{2}+\mathrm{OH}^{-} \leftrightarrow \mathrm{CoOOH}+\mathrm{H}_{2} \mathrm{O}+\mathrm{e}^{-}$

$\mathrm{CoOOH}+\mathrm{OH}^{-} \leftrightarrow \mathrm{CoO}_{2}+\mathrm{H}_{2} \mathrm{O}+\mathrm{e}^{-}$
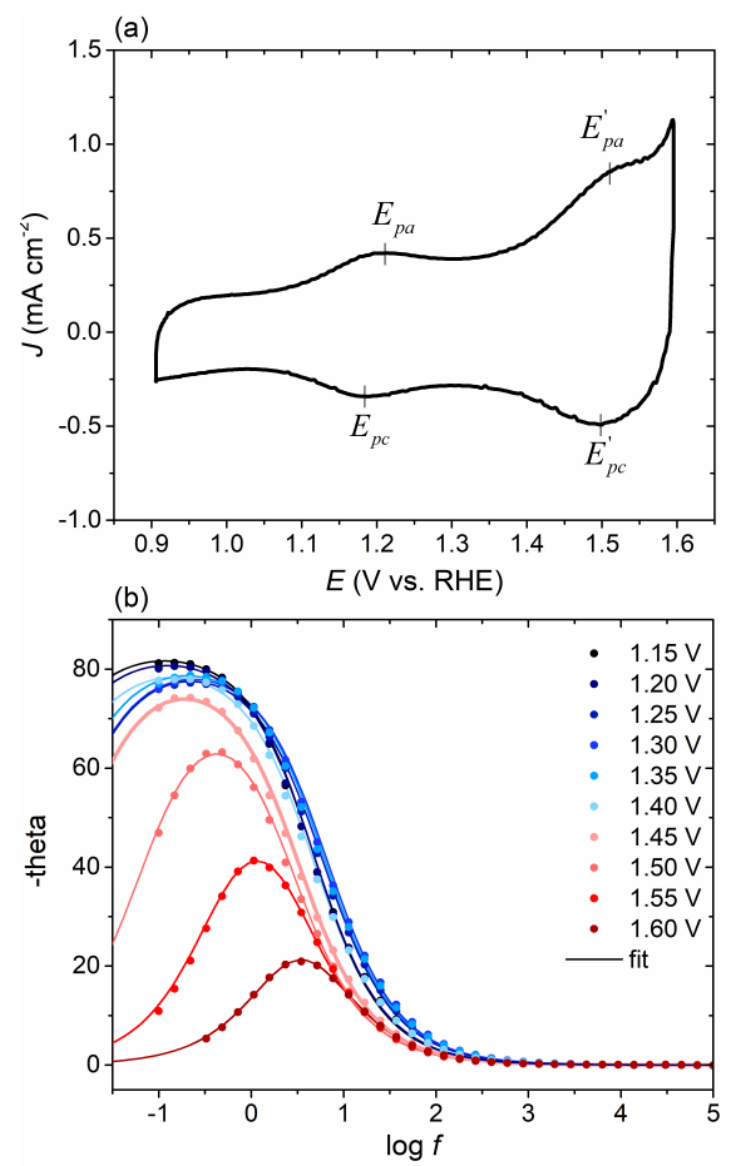

Figure 1. (a) Cyclic voltammogram of $\mathrm{CoOOH}$ in $0.1 \mathrm{M} \mathrm{Fe}-$ free $\mathrm{KOH}$ electrolyte. Substrate: carbon cloth; and scan rate: $100 \mathrm{mV} \mathrm{s}^{-1}$. (b) Bode plot of as-prepared $\mathrm{CoOOH}$ with respect to the applied potential. Conditions: Au substrate, o.1 M Fe-free KOH electrolyte.

Based on ICP-OES, the total number of Co atoms in the $\mathrm{CoOOH}$ film is about $13.10 \pm 1.10 \mathrm{nmol}$, and the total number of lattice oxygen is about $26.00 \pm 2.20 \mathrm{nmol}$. Based on the ECSA, the number of surface Co atoms is about $12.50 \pm 2.90$ $\mathrm{nmol}$, indicating that more than $95 \%$ of the electrodeposited Co ions is on the surface. By integrating the charge of $\mathrm{Co}(\mathrm{III})$ to $\mathrm{Co}(\mathrm{IV})$ transition (between 1.30 and $1.56 \mathrm{~V}$ vs. RHE, Figure 1a), we estimate the number of active surface Co atoms as about $1.50 \mathrm{nmol}$ of Co. This number corresponds to about $12 \%$ of the total surface Co atoms (with respect to the total number of surface atoms based on ECSA). This result agrees with the work of Baltruschat et. $\mathrm{al}^{30}$, who reported that $12 \%$ of the surface cobalt atoms were catalytically active in the case of $50 \mathrm{~nm}$ thick $\mathrm{Co}_{3} \mathrm{O}_{4}$.

2.2 Electrochemical Impedance Analysis. Electrochemical impedance spectroscopy (EIS) was applied to elucidate the redox processes at different potentials. The EIS response could be fit by a Randles circuit comprising three elements: a resistor $\left(R_{e}\right)$ for the electrolyte resistance, a resistor $\left(\mathrm{R}_{\mathrm{ct}}\right)$ related to the charge-transfer resistance of an electrochemical process, and a constant phase element (CPE) which simulates the double-layer capacitance (Figure $S_{5} b$ ). The Bode plot (Figure $1 b$ ) is dominated by one 
interfacial charge-transfer process at the $\mathrm{CoOOH}$-electrolyte interface. The electrochemical processes related to the oxidation of $\mathrm{Co}$ (II) to $\mathrm{Co}$ (III) (at about 1.20 V) and the oxidation of the Au substrate (at about 1.30 V, Figure S2b) were observed by the EIS; the two processes had large time constants (Figure S6). At 1.45 V and above, the phase angle maximum in the Bode plot moved to lower values while the charge-transfer resistance and the time constant decrease with increasing applied potentials (Figure $\mathrm{S}_{5}$ and S6). These changes were attributed to the OER process, which had an onset potential of $1.45 \mathrm{~V}$. The oxidation of $\mathrm{CoOOH}$ to $\mathrm{CoO}_{2}$, observed in $\mathrm{CV}$ at about $1.5 \mathrm{~V}$, could not be detected by EIS due to overlap with the OER process.

2.3 X-ray Absorption Spectroscopy. To probe the oxidation state and reveal the structural transformation at various applied potentials, in situ X-ray absorption spectroscopy (XAS) was conducted. Figure za displays the X-ray absorption near-edge structure (XANES) that reveals the average oxidation state of $\mathrm{Co}$ ions at various potentials as well as reference samples including $\mathrm{Co}$ foil (o), $\mathrm{CoO}(\mathrm{II}), \mathrm{Co}_{3} \mathrm{O}_{4}$ (II and III), and $\mathrm{Co}_{2} \mathrm{O}_{3}$ (III). The linear relationship of the oxidation state is illustrated in Figure 2b. Initially, the oxidation state of $\mathrm{Co}$ ion in the dry sample of $\mathrm{CoOOH}$ was

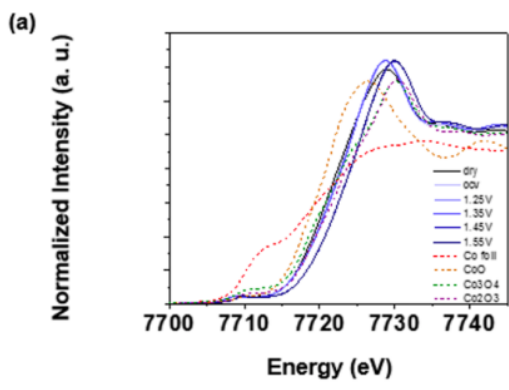

(b)

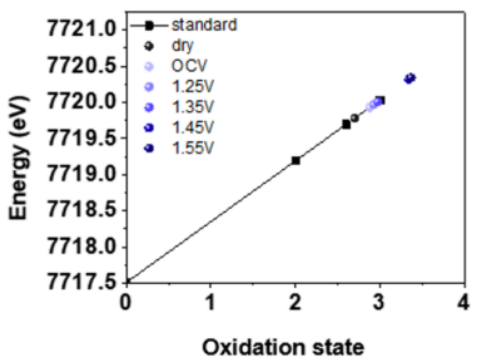

between (II) and (III), being slightly higher than that of $\mathrm{Co}_{3} \mathrm{O}_{4}$. Thus, the Co ions were mostly $\mathrm{Co}$ (III), mixed with some $\mathrm{Co}$ (II). After immersing in the electrolyte, the oxidation state of Co ions slightly increased, which might be attributed to the oxidation of some residual $\mathrm{Co}$ (II) into $\mathrm{Co}(\mathrm{III})$ by the $\mathrm{OH}^{-}$electrolyte at unsaturated surface sites. ${ }^{31}$ The average oxidation state of Co ions gradually increased with increasing applied potential. At $1.45 \mathrm{~V}$, the oxidation state increased dramatically to higher than Co(III), indicating the appearance of $\mathrm{Co}(\mathrm{IV})$ ions. Note that the oxidation state continued to slightly increase at $1.55 \mathrm{~V}$, suggesting the further formation of $\mathrm{Co}(\mathrm{IV})$ in the catalyst.

Regarding the local structural evolution in $\mathrm{CoOOH}$, EXAFS reveals that (Figure $2 \mathrm{c}$ and $\mathrm{S}_{7}$ ) there were two scattering paths around the absorbing Co ions. The first peak located at $1.90 \AA$ was the first coordination shell of the CoO scattering path, and the second peak located at $2.84 \AA$ could be referred to the second coordination shell of $\mathrm{Co}$ Co path. To further understand the structural parameters under various conditions, the quantitative analysis involving a simulation of $\mathrm{k}^{3}$-weighted EXAFS spectra was conducted (Figure S8 and Table $\mathrm{S}_{3}$ ).

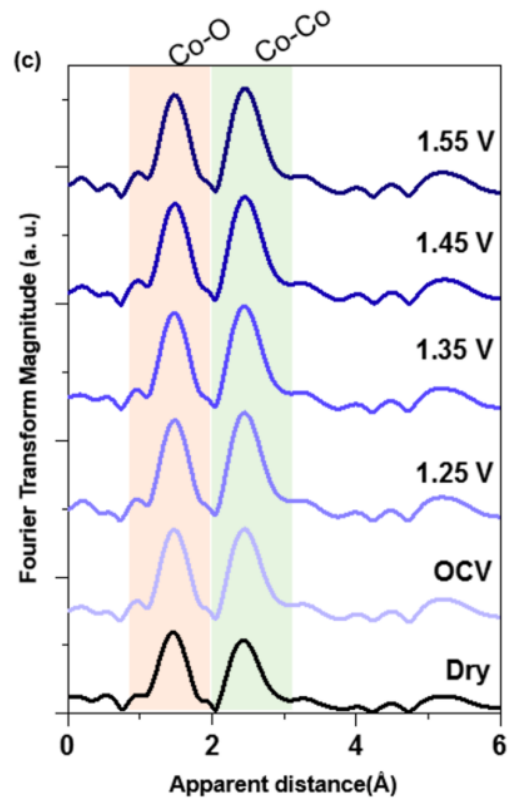

Figure 2. Operando X-ray absorption spectroscopy. (a) XANES spectra of $\mathrm{CoOOH}$ at various potentials, as well as reference samples $\mathrm{Co}$ foil (red), $\mathrm{CoO}$ (brown), $\mathrm{Co}_{3} \mathrm{O}_{4}$ (green), and $\mathrm{Co}_{2} \mathrm{O}_{3}$ (purple), (b) linear relationship of oxidation state. (c) Fourier transform of Co K-edge EXAFS spectra w/o phase correction for $\mathrm{CoOOH}$ under various conditions.

Upon increasing the potential, the coordination number of Co-O path increased from about 5.5 to 6.0 and then stayed at a constant value of approximately 6.o, while the interatomic distance gradually decreased from 1.90 to $1.86 \AA$. This finding indicates that the initial stage of the catalyst contains a mixture of $4^{-}$or 5 -coordinated $\mathrm{Co}(\mathrm{II})\left(\mathrm{R}_{\mathrm{Co}-\mathrm{O}}=\right.$ $2.043 \AA ̊)$ ions and 6-coordinated $\mathrm{Co}(\mathrm{III})\left(\mathrm{R}_{\mathrm{Co}-\mathrm{O}}=1.895 \AA\right)$ ions, and the $\mathrm{Co}$ (II) ions were oxidized to $\mathrm{Co}$ (III) below $1.45 \mathrm{~V} .^{10}$ At $1.45 \mathrm{~V}$, there were no longer $\mathrm{Co}(\mathrm{II})$ ions, so that the coordination number of $\mathrm{Co}-\mathrm{O}$ path reached a constant value of 6.o. On the other hand, the coordination number of Co-Co path slightly increased from 5.1 to 5.7 while the interatomic distances of Co-Co stayed at $2.84 \AA$ under various conditions. These changes were due to the oxidation of residual $\mathrm{Co}$ (II) to $\mathrm{Co}(\mathrm{III})$. Notably, the local structures were almost identical even when the potentials were increased to $1.45 \mathrm{~V}$ and above, while the oxidation state of Co increased. This observation was attributed to a similar structure between $\mathrm{Co}(\mathrm{III})$ and $\mathrm{Co}(\mathrm{IV})$ oxyhydroxides, with no significant change in the coordination number as well as the interatomic distance. A similar observation was made previously on $\mathrm{CoO}_{x}$ deposited on $\mathrm{Au}(111)$, where the 
spectral feature at high potentials was correlated with $\mathrm{Co}(\mathrm{IV})$ in a non-stoichiometric $\mathrm{H}_{x} \mathrm{CoO}_{2}(\mathrm{x}<1)$ phase, $\beta$ $\mathrm{H}_{0.5} \mathrm{CoO}_{2}$. No major difference was found in the structural parameters between $\beta-\mathrm{CoOOH}$ (with $\mathrm{Co}(\mathrm{III})$ ) and $\beta$ $\mathrm{H}_{0.5} \mathrm{CoO}_{2} .^{15}$ Likewise, a recent XAS study showed similar structural parameters for $\mathrm{Co}(\mathrm{III}) \mathrm{OOH}$ and $\mathrm{Co}(\mathrm{III} / \mathrm{IV}) \mathrm{OOH}_{1-x} .^{31}$

\subsection{In situ Surface-Enhanced Raman Spectroscopy (SERS)}

2.4.1. Potential-dependent spectra. The in situ SERS spectra of $\mathrm{CoOOH}$ are shown in Figure 3. Two broad spectral features, corresponding to $\mathrm{A}_{\mathrm{g}}$ and $\mathrm{E}_{\mathrm{g}}$ vibrational modes of Co-O, were visible at around $608 \mathrm{~cm}^{-1}$ and $508 \mathrm{~cm}^{-1}$ already at the open circuit potential (OCP). Such a spectrum is commonly attributed to amorphous $\mathrm{CoOOH} .{ }^{16,32-34}$ Thus, the as-prepared sample contained a large portion of $\mathrm{CoOOH}$, probably in a mixture with other forms of Co oxides, notably $\mathrm{Co}(\mathrm{OH})_{2}$, that were invisible in the Raman spectrum. The formation of $\mathrm{CoOOH}$ was a result of the anodic oxidation process in the synthesis. When the applied potential was increased up to $1.25 \mathrm{~V}$, these two bands were shifted to slightly lower frequencies, from 608 to $600 \mathrm{~cm}^{-1}$ and from 508 to $500 \mathrm{~cm}^{-1}$, respectively. As both CV and EIS data indicate that oxidation of $\mathrm{Co}$ (II) to $\mathrm{Co}$ (III) should complete at $1.25 \mathrm{~V}$ and above, the small spectral change probably reflected the conversion of residual Co(II) species into $\mathrm{CoOOH}$, which resulted in better-resolved spectra. Above $1.35 \mathrm{~V}$, the two Co-O peaks gradually redshifted indicating another phase transformation (Figure 3). The positions of the two peaks stabilized at around $581 \mathrm{~cm}^{-1}$ and $474 \mathrm{~cm}^{-1}$ at $1.50 \mathrm{~V}$ and above (Figure 3 and Figure S9a). The final peaks are attributed to the $A_{1 g}$ and $E_{g}$ vibrational modes of a disordered $\mathrm{CoO}_{2}$ (Figure Siob).34-36

Yeo and Bell previously reported a Raman study of $\mathrm{CoO}_{x}$ deposited on $\mathrm{Au}(111) .{ }^{18}$ They measured two type of samples: 0.4 and 87 monolayers (MLs) of $\mathrm{CoO}_{x}$. For the 87 ML sample, the as-prepared compound was $\mathrm{Co}_{3} \mathrm{O}_{4}$, which exhibited multiple peaks in the region of $485-691 \mathrm{~cm}^{-1}$. Upon oxidation, the peaks due to $\mathrm{Co}_{3} \mathrm{O}_{4}$ attenuated, and two new peaks at 503 and $565 \mathrm{~cm}^{-1}$ appeared, which were assigned to $\mathrm{CoOOH}$. For the $0.4 \mathrm{ML}$ sample, the as-prepared compound, assigned to a dispersed $\mathrm{CoO}_{x}$, exhibited a main Raman peak at $609 \mathrm{~cm}^{-1}$ at o $\mathrm{V}$ (vs. $\mathrm{Hg} / \mathrm{HgO}$, equivalent to $0.878 \mathrm{~V}$ vs. RHE). ${ }^{18}$ This peak red-shifted to $579 \mathrm{~cm}^{-1}$ at 1.578 $\mathrm{V}$ (vs. RHE), and the shift was attributed to the formation of a $\mathrm{Co}(\mathrm{IV})$ phase. ${ }^{18}$ The electrodeposition procedure in the current study is similar to the procedure employed in the work of Yeo and Bell. ${ }^{18}$ Our $\mathrm{CoOOH}$ film has a thickness of 2-3 nm, so we expect our sample to be similar to the $0.4 \mathrm{ML}$ sample of Yeo and Bell. Indeed, their Raman spectra were similar. Although not noted in the previous study, the spectrum of the $0.4 \mathrm{ML}$ sample before oxidation had a broad absorption at around $500 \mathrm{~cm}^{-1}$. Upon oxidation of Co(III) to Co(IV), similar red-shift of the $608 \mathrm{~cm}^{-1}$ peak was observed for both the o.4 $\mathrm{ML} \mathrm{CoO}_{x}$ and our $\mathrm{CoOOH}$ samples. The small red-shift of the $508 \mathrm{~cm}^{-1}$ peak was visible for our $\mathrm{CoOOH}$ sample, but less obvious for the $0.4 \mathrm{ML}$ sam- ple because again only a broad feature was seen. We suspect that due to a higher spectroscopic resolution of our experimental set-up, we were able to detect and differentiate the peaks at $508-500 \mathrm{~cm}^{-1}$ for our samples, unlike in the previous study. ${ }^{18}$

$\mathrm{Au}$ might promote the OER activity of $\mathrm{CoO}_{x}$ due to a more facile oxidation of $\mathrm{Co}$ (III) to $\mathrm{Co}$ (IV) as well as to a reduced resistance of the catalyst. ${ }^{18,37-39}$ However, Raman peaks attributed to $\mathrm{CoO}_{2}$ were observed prior to OER for catalysts deposited on FTO $^{35}$ and Pt. ${ }^{34}$ Thus, we expect the spectral features observed in this study to arise from the $\mathrm{CoOOH}$ catalyst itself, and are not limited to samples on $\mathrm{Au}$. This judgement is supported by the agreement in the observations of potential-dependent oxidation of Co(III) to Co(IV) by CV, EIS, XAS, and Raman for samples deposited on different substrates (Au for EIS and Raman and carbon cloth for CV and XAS).

In the SERS spectra, a broad band was observed at the $800-1200 \mathrm{~cm}^{-1}$ range (culminating at ca. $1075 \mathrm{~cm}^{-1}$ ) at $1.35 \mathrm{~V}$ and above. The position of the band remained unchanged with increasing potential. The intensity of the band increases with increasing potential, suggesting an increase in the concentration of the involved species at higher potentials (Figure S9b, SI). The position of the band is similar to that of the IR band of a Co-superoxide intermediate (at $1068 \mathrm{~cm}^{-1}$ ) detected during photolytic OER catalyzed by spinel $\mathrm{Co}_{3} \mathrm{O}_{4}$ in near-neutral water. ${ }^{12}$ Similar Raman bands were also observed in nickel and nickel iron oxyhydroxides, where those bands were assigned to the so-called active oxygen species..$^{40-42}$ The Raman spectra of the reference compounds $\mathrm{CO}_{3} \mathrm{O}_{4}, \mathrm{LiCoO}_{2}$, and $\mathrm{Co}(\mathrm{OH})_{2}$ are shown in Figures Sioa-c. 

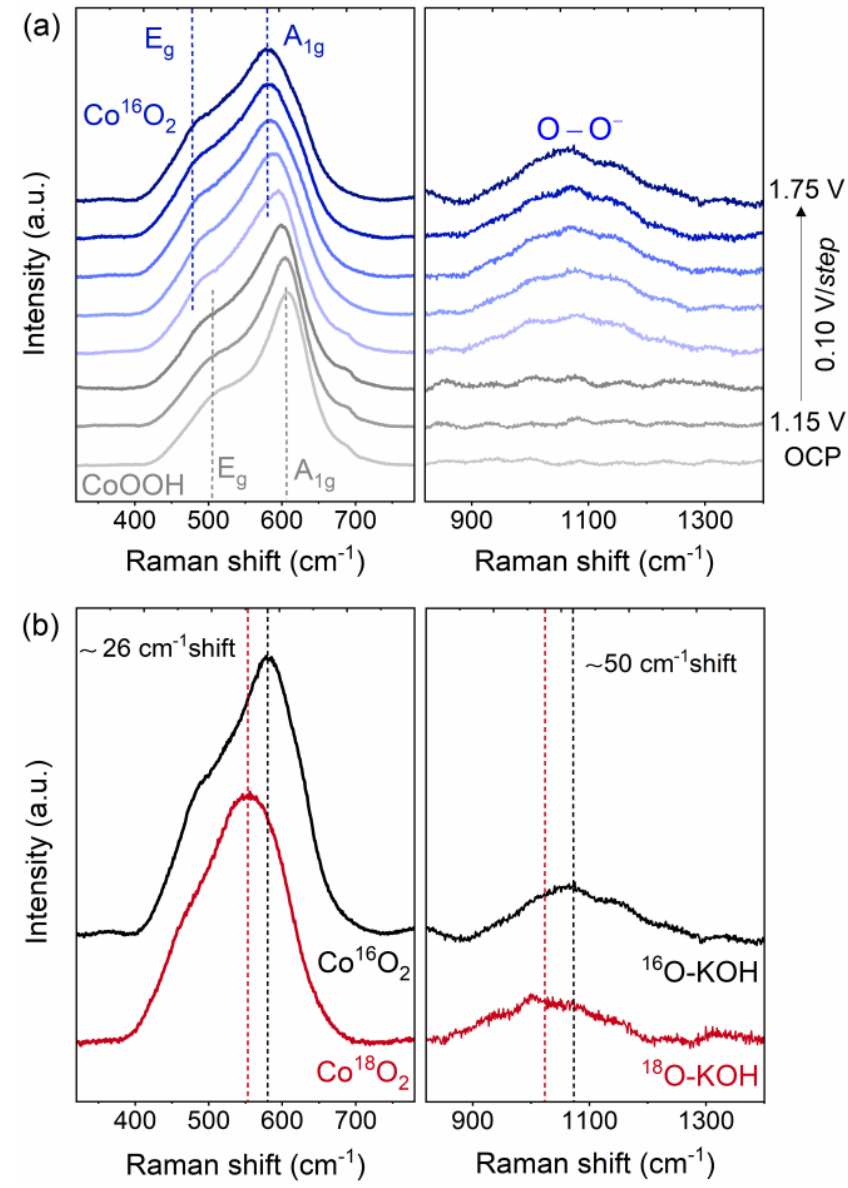

Figure 3. (a) In situ Raman spectra of $\mathrm{CoOOH}$ at increasing applied potential from OCP to $1.75 \mathrm{~V}$ (o.1 V per step) in o.1 M Fe-free ${ }^{16} \mathrm{O}-\mathrm{KOH}$. Left, the $\mathrm{Co}-\mathrm{O}$ bands; right, bands attributed to active oxygen species. (b) In situ Raman spectra of $\mathrm{Co}^{16} \mathrm{O}_{2}$ in o.1 M Fe-free ${ }^{16} \mathrm{O}-\mathrm{KOH}$ (black) and of $\mathrm{Co}^{18} \mathrm{O}_{2}$ in o.1 $\mathrm{M}$ Fe-free ${ }^{18} \mathrm{O}-\mathrm{KOH}$ (red) recorded at $1.75 \mathrm{~V}$ vs. RHE. The peak of the $\mathrm{A}_{1 \mathrm{~g}}$ mode of $\mathrm{CoO}_{2}$ shifted by $\sim 26 \mathrm{~cm}^{-1}$, while the peak of the superoxidic species $\mathrm{OO}^{-}$at the higher wavenumbers shifted by $\sim 50 \mathrm{~cm}^{-1}$.

2.4.2. ${ }^{18} \mathrm{O}$-labelling experiments. We performed isotope labelling experiments to probe the nature of the active oxygen species. The as-prepared $\mathrm{CoOOH}$ films were subjected to potentiostatic electrolysis at $1.75 \mathrm{~V}$ in $0.1 \mathrm{M} \mathrm{Fe}$ free ${ }^{18} \mathrm{O}-\mathrm{KOH}$. After electrolysis, the peak at $581 \mathrm{~cm}^{-1}$ related to the $\mathrm{A}_{1 \mathrm{~g}}$ vibrational mode of $\mathrm{CoO}_{2}$ shifted by ca. 26 $\mathrm{cm}^{-1}$ compared to the peak from ${ }^{16} \mathrm{O}$-labelled sample, confirming the complete ${ }^{18} \mathrm{O}$ labelling of the lattice $\mathrm{O}$ in $\mathrm{CoO}_{2}$ (Figure 3). The broad peak at the range of $800-1200 \mathrm{~cm}^{-1}$ shifted by approximately $50 \mathrm{~cm}^{-1}$, indicating the replacement of two ${ }^{16} \mathrm{O}$ atoms by two ${ }^{18} \mathrm{O}$ atoms. Thus, the broad peak can be assigned to a superoxidic species ( $\left.\mathrm{CoOO}^{-}\right)$similar to the Co-superoxo species on $\mathrm{Co}_{3} \mathrm{O}_{4}{ }^{12}$ as well as the adsorbed active oxygen observed on $\mathrm{NiO}_{x} \mathrm{H}_{y}$ and $\mathrm{NiFeO}_{x} \mathrm{H}_{y}$ catalysts. ${ }^{41-44}$ This assignment is also consistent with a previously reported Raman peak at ca. $1075 \mathrm{~cm}^{-1}$ for the $\mathrm{OO}^{-}$ stretch mode of dibridged $\mu$-superoxo-dicobalt complexes ${ }^{45}$ as well as the Raman peak position of $\mathrm{v}(\mathrm{OO})$ in $\mu$ - amido- $\mu$-hyperoxo bis[tetraminecobalt(III)] complexes at $1075 \mathrm{~cm}^{-1}$, which was shifted to $1015 \mathrm{~cm}^{-1}$ for ${ }^{18} \mathrm{O}$-substituted analogous. ${ }^{46}$ Our result contradicts a previous study where a broad Raman band centred at $1068 \mathrm{~cm}^{-1}$ from spinel $\mathrm{Co}_{3} \mathrm{O}_{4}$ was assigned to a surface superoxide species. ${ }^{47}$ In that study, an oxygen isotopic shift of $25 \mathrm{~cm}^{-1}$ was observed in ${ }^{18} \mathrm{O}-\mathrm{KOH}$, indicating the exchange of only one $\mathrm{O}$ atom. It might be that the observed peak is due to a crystalline $\mathrm{CoOOH}$ phase, which was shown to exhibit a broad Raman peak in a similar region. ${ }^{22,48}$

We then performed isotope exchange experiments to probe how lattice oxygen and active oxygen species were exchanged with electrolyte. For this purpose, we monitored the in situ Raman spectra of both ${ }^{16} \mathrm{O}$ - and ${ }^{18} \mathrm{O}-\mathrm{la}$ belled catalysts in $0.1 \mathrm{M}$ Fe-free ${ }^{16} \mathrm{O}-\mathrm{KOH}$ and ${ }^{18} \mathrm{O}-\mathrm{KOH}$ from 1.15 to 1.75 V (Figures Sina-c). At each potential, the spectrum was collected after 10 min of electrolysis. For ${ }^{16} \mathrm{O}-$ labelled catalyst, the freshly prepared $\mathrm{CoOOH}$ was used; for ${ }^{18} \mathrm{O}$-labelled catalyst we used $\mathrm{Co}^{18} \mathrm{O}_{2}$ as described in Figure 3. The peak positions for $\mathrm{Co}^{16} \mathrm{OOH}$ in ${ }^{16} \mathrm{O}-\mathrm{KOH}$ and $\mathrm{Co}^{18} \mathrm{O}_{2}$ in ${ }^{18} \mathrm{O}-\mathrm{KOH}$ serve as reference points for fully ${ }^{16} \mathrm{O}$ and ${ }^{18} \mathrm{O}$-labelled samples, respectively. At $1.15 \mathrm{~V}$ to $1.25 \mathrm{~V}$, the observed isotopic shifts of $\mathrm{Co}-\mathrm{O}$ bands were smaller than expected even for fully ${ }^{16} \mathrm{O}$ - and ${ }^{18} \mathrm{O}$-labelled samples (Figure Sira-c), which was likely due to the poor resolution of the Raman peaks at these potentials. At 1.35 V and above, the observed isotopic shifts were consistent with fully ${ }^{16} \mathrm{O}-$ and ${ }^{18} \mathrm{O}$-labelled samples, indicating that the resolution of Raman peaks was sufficient for analysis at these potentials (Figure 4).

For ${ }^{16} \mathrm{O}$-labelled $\mathrm{CoOOH}$ in ${ }^{18} \mathrm{O}-\mathrm{KOH}$, both the $\mathrm{A}_{1 \mathrm{~g}}$ band of $\mathrm{Co}-\mathrm{O}$ and the $\mathrm{OO}^{-}$band have peak positions that were nearly identical to those of ${ }^{18} \mathrm{O}$-labelled $\mathrm{CoO}_{2}$ in ${ }^{18} \mathrm{O}-\mathrm{KOH}$, indicating that both lattice $\mathrm{O}^{-}$and $\mathrm{OO}^{-}$atoms in $\mathrm{CoOOH}$ quickly exchanged with the electrolyte during the operando Raman experiments, at potentials no higher than 1.35 V. For ${ }^{18} \mathrm{O}$-labelled $\mathrm{CoO}_{2}$ in ${ }^{16} \mathrm{O}-\mathrm{KOH}$, the peak positions of the $\mathrm{A}_{\mathrm{g}}$ band of $\mathrm{Co}-\mathrm{O}$ and $\mathrm{OO}^{-}$band were close to those of ${ }^{18} \mathrm{O}$-labelled $\mathrm{CoO}_{2}$ in ${ }^{18} \mathrm{O}-\mathrm{KOH}$ at $1.35 \mathrm{~V}$, and they gradually moved towards the positions of ${ }^{16} \mathrm{O}$-labelled $\mathrm{CoOOH}$ in ${ }^{16} \mathrm{O}-\mathrm{KOH}$. Even at $1.75 \mathrm{~V}$, the peak positions were between those of fully ${ }^{16} \mathrm{O}$ - and ${ }^{18} \mathrm{O}$-labelled samples, leading towards the fully ${ }^{16} \mathrm{O}$-labelled sample. This observation indicates that both lattice $\mathrm{O}$ and $\mathrm{OO}^{-}$atoms in $\mathrm{CoO}_{2}$ significantly exchanged with the electrolyte only at $1.45 \mathrm{~V}$ and above in the time scale of the operando Raman experiments. Moreover, the exchange was incomplete.

To further probe whether the lattice oxygen and active oxygen species exchange with the electrolyte through the OER, we applied a three-step isotope labelling and monitoring approach (Figure 5). First, an as-prepared $\mathrm{Co}^{16} \mathrm{OOH}$ film was labelled with ${ }^{18} \mathrm{O}$ by electrochemical oxidation at $1.75 \mathrm{~V}$ in $0.1 \mathrm{M}$ Fe-free ${ }^{18} \mathrm{O}-\mathrm{KOH}$ to give $\mathrm{Co}^{18} \mathrm{O}_{2}$. Next, the electrolyte was replaced with o.1 M Fe-free ${ }^{16} \mathrm{O}-\mathrm{KOH}$, while the potential of the electrochemical cell was set to $1.45 \mathrm{~V}$ to avoid the reduction of $\mathrm{CoO}_{2}$ to $\mathrm{CoOOH}$. 
(a)

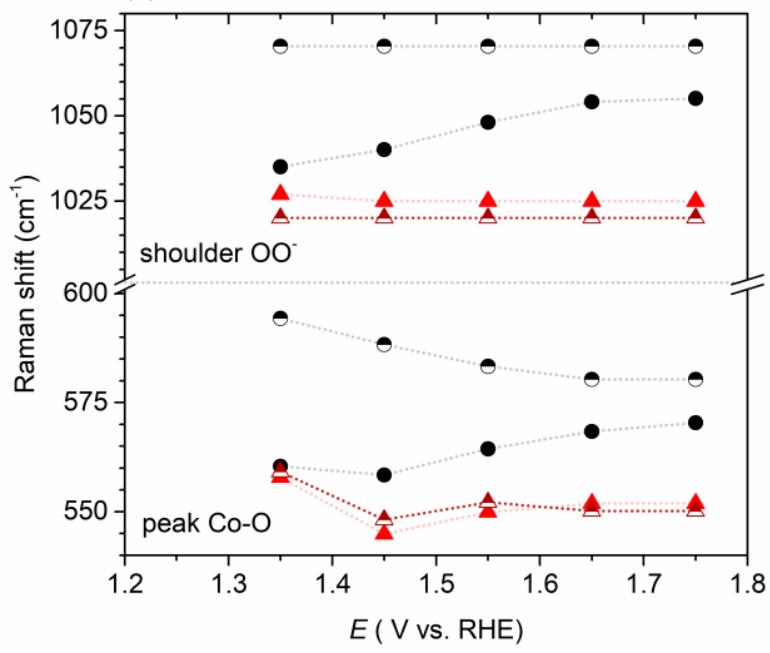

(b)

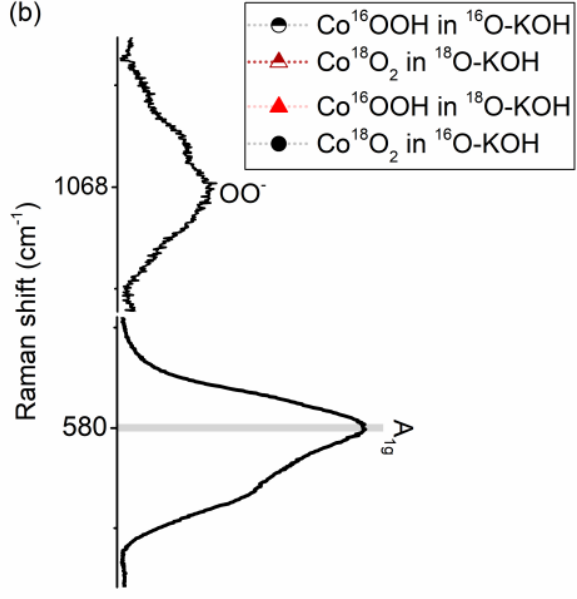

Figure 4. (a) Raman peak positions of the two main bands corresponding to $\mathrm{CoO}_{2}$ and $\mathrm{OO}^{-}$of 4 different samples: (black half-full circle) freshly prepared $\mathrm{Co}^{16} \mathrm{OOH}$ in o.1 $\mathrm{M}$ Fe-free ${ }^{16} \mathrm{O}-\mathrm{KOH}$; (red half-full triangle) labelled $\mathrm{Co}^{18} \mathrm{O}_{2}$ in o.1 $\mathrm{M}$ Fe-free ${ }^{18} \mathrm{O}-\mathrm{KOH}$; (red triangle) freshly prepared $\mathrm{Co}^{16} \mathrm{OOH}$ in o.1 $\mathrm{M}$ Fe-free ${ }^{18} \mathrm{O}-\mathrm{KOH}$; (black circle) labelled $\mathrm{Co}^{18} \mathrm{O}_{2}$ in o.1 $\mathrm{M}$ Fe-free ${ }^{16} \mathrm{O}-\mathrm{KOH}$. (b) Typical Raman peaks of freshly prepared $\mathrm{Co}^{16} \mathrm{OOH}$ in o.1 $\mathrm{M}$ Fe-free ${ }^{16} \mathrm{O}-\mathrm{KOH}$ as a reference.

Once the electrolyte was replaced, we recorded the in situ Raman spectra of $\mathrm{Co}^{18} \mathrm{O}_{2}$ in ${ }^{16} \mathrm{O}-\mathrm{KOH}$ from $1.45 \mathrm{~V}$ to 1.75 $\mathrm{V}$ (with an interval of o.10 $\mathrm{V}$ ). At each potential, the spectrum was collected after $10 \mathrm{~min}$ of electrolysis. We chose the $1.45 \mathrm{~V}$ as starting potential because, according to electrochemical data at this potential, the oxidation of $\mathrm{Co}(\mathrm{OH})_{2}$ to $\mathrm{CoOOH}$ as well as $\mathrm{CoOOH}$ to $\mathrm{CoO}_{2}$ is completed and only OER is the relevant charge transfer process. The Raman peaks related to the $A_{1 g}$ and $E_{g}$ vibrational modes of $\mathrm{CoO}_{2}$ as well as $\mathrm{OO}^{-}$were shifted to higher frequencies upon OER (Figure $5 \mathrm{~b}$ ), indicating that both lattice $\mathrm{O}$ and $\mathrm{OO}^{-}$can exchange with electrolyte through the OER process. The peaks were not completely shifted to the positions for a fully ${ }^{16} \mathrm{O}$ labelled $\mathrm{CoO}_{2}$ sample at all potential measured. The most significant shift was observed at $1.75 \mathrm{~V}$, where the $A_{1 \mathrm{~g}}$ Co-O peak blueshifted by $17 \mathrm{~cm}^{-1}$, about $65 \%$ of the complete shift of about $26 \mathrm{~cm}^{-1}$ for a full isotopic exchange. Likewise, the $\mathrm{OO}^{-}$peak shifted by about $70 \%$ of the value expected for a full isotopic exchange.

In our experiments, 10 min of electrolysis was conducted before a Raman spectrum was taken. By integrating the charge passed through electrolysis, we estimated the number of mol of $\mathrm{O}$ atoms that were evolved as $\mathrm{O}_{2}$ (SI, Figure S12). At $1.45 \mathrm{~V}$, this number corresponded to about $54 \%$ of the total number of lattice oxygen in the catalyst. At potentials from 1.55 V and higher, the $\mathrm{O}$ evolved at each step is sufficient to enable the complete exchange of lattice oxygen (see section $7, \mathrm{SI}$ ). The potential-dependent and incomplete $\mathrm{O}$ isotope exchange might be due to several factors: 1. Not all surface sites in $\mathrm{CoO}_{2}$ are active. 2. A higher potential leads to a higher percentage of surface active sites. 3. The exchange through the whole lattice is slow at the time scale of the experiments.

2.4.3. D-labelling experiments. In o.1 $\mathrm{M}$ Fe-free $\mathrm{KOD}$, the $\mathrm{A}_{1 \mathrm{~g}}$ peak of $\mathrm{CoO}_{2}$ appeared at about $571 \mathrm{~cm}^{-1}$, which is about $10 \mathrm{~cm}^{-1}$ lower than that in o.1 $\mathrm{M} \mathrm{Fe}$-free $\mathrm{KOH}$ (Figure ${ }^{\mathrm{C}}$ ).
The shift suggests that there are still $\mathrm{OH}$ groups in $\mathrm{CoO}_{2}$, and the $\mathrm{OH}$ group can exchange with $\mathrm{OD}$ in the electrolyte. Alternatively, the shift might be due to the hydrogenbonding interaction of $\mathrm{Co}-\mathrm{O}$ with water or $\mathrm{OH}^{-}$. The $\mathrm{OO}^{-}$ peak, however, remained at the same position in KOD as in $\mathrm{KOH}$ (Figure $5 \mathrm{c}$ ). This result suggests that the superoxide moiety is neither protonated nor having a hydrogen bonding with a nearby $\mathrm{OH}$ group, in contrast to the Cosuperoxide intermediate in photocatalytic OER in nearneutral solutions catalyzed by $\mathrm{Co}_{3} \mathrm{O}_{4} \cdot{ }^{12}$ According to D-labelling experiments, that superoxide had hydrogen-bonding interaction with a nearby $\mathrm{OH}$ group, which led to a $\mathrm{D}$ isotope shift of $38 \mathrm{~cm}^{-1}$ in the FT-IR spectrum.

2.5 Electrokinetic study. The Tafel slopes of OER in various concentrations of Fe-free $\mathrm{KOH}$ (o.01 to 1.50 M) in the

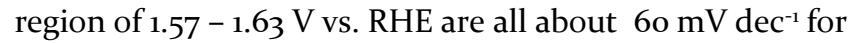
catalysts deposited on both carbon cloth and Au substrates (Figure 6a, Figure Siza and Table $\mathrm{S}_{4}, \mathrm{SI}$ ), which is a typical value for cobalt oxides in Fe-free $\mathrm{KOH} .{ }^{25,49}$ The similar Tafel slopes for catalysts on $\mathrm{Au}$ and carbon cloth suggest that the reaction mechanism is the same on both substrates. Previous studies have observed a similar Tafel slope for cobalt oxide (about $60 \mathrm{mV} \mathrm{dec}^{-1}$ ) on different substrates and in a wide $\mathrm{pH}$ range $\left(3 \cdot 5^{-14}\right)$ as well.14,37,49 This Tafel slope suggests that the OER proceeds by a pre-equilibrium step involving one-electron transfer and followed by a ratedetermining step involving only a chemical reaction. .4,49,50 $^{4}$ The catalytic activity increases with increasing hydroxide concentration (Figure 6b). The potential required to reach $1 \mathrm{~mA} \mathrm{~cm}{ }^{-2}$ (vs. $\mathrm{Ag} / \mathrm{AgCl}$ ) decreased by about 70.0 $\pm 1.0 \mathrm{mV}$ per unit of $\log \left[\mathrm{OH}^{-}\right]$(Figure $6 \mathrm{c}$ ). Based on equation $3,^{5^{1}}$ the catalytic activity (current density) has an approximately first-order dependence on the concentration of $\left[\mathrm{OH}^{-}\right]$. (This result indicates that in total only one hydroxide is transferred during the pre-equilibrium and rate-determining steps. ${ }^{14}$ ) 
$\left(\frac{\partial E}{\partial \mathrm{pH}}\right)_{j}=-\left(\frac{\partial E}{\partial \log j}\right)_{\mathrm{pH}}\left(\frac{\partial \log j}{\partial p H}\right)_{E}$

(a)
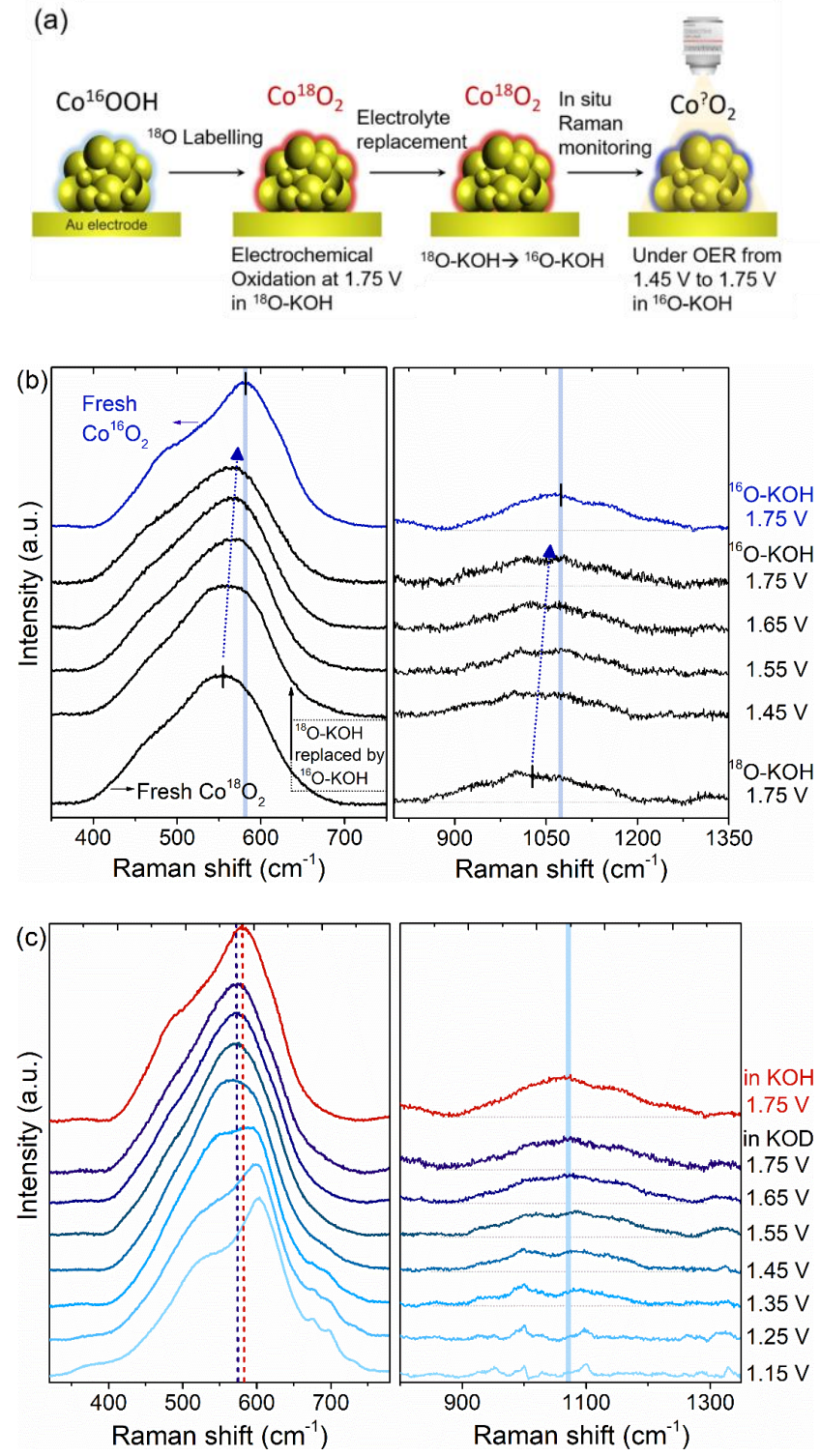

Figure 5. (a) Schematic representation of the procedure followed to investigate the participation of the lattice oxygen in the OER. Conditions: $0.1 \mathrm{M}$ Fe-free ${ }^{18} \mathrm{O}-\mathrm{KOH}$ and ${ }^{16} \mathrm{O}-\mathrm{KOH}$. (b) In situ SERS of labelled $\mathrm{Co}^{18} \mathrm{O}_{2}$ in $0.1 \mathrm{M}$ Fefree ${ }^{16} \mathrm{O}-\mathrm{KOH}$. The peaks blueshift as a function of the applied potential. (c) In situ SERS of $\mathrm{Co}^{16} \mathrm{OOH}$ in $0.1 \mathrm{M} \mathrm{Fe}-$ free KOD.

The peak potentials for the $\mathrm{Co}(\mathrm{III}) / \mathrm{Co}(\mathrm{IV})$ couple (due to overlap of the oxidation current with OER, $\mathrm{E}_{\mathrm{pc}}$ ' was used) shift by about $92.0 \pm 1.5 \mathrm{mV}$ per unit of [OH$\left.{ }^{-}\right]$(Figure 6d, Figure Sizb, SI). A similar super-Nernstian behavior was previously observed for other metal oxides. ${ }^{29,52-55}$ For example, both the $\mathrm{Ni}(\mathrm{II}) / \mathrm{Ni}(\mathrm{III})$ redox couple in electrodeposited $\mathrm{Ni}(\mathrm{OH})_{2}$ and the $\mathrm{Fe}(\mathrm{II}) / \mathrm{Fe}(\mathrm{III})$ redox couple in $\mathrm{Fe}(\mathrm{OH})_{2}$ exhibit a shift of $-88 \mathrm{mV} / \mathrm{pH} .{ }^{55-57}$ According to literature, such a super-Nernstian behavior is characteristic of hydrous or hyper-extended oxides and arises from the hydrolysis of the system during the redox transition. ${ }^{29,56-59}$ LSV curves of freshly prepared $\mathrm{CoOOH}$ were recorded in Fe-free $\mathrm{KOH}$ and KOD solutions with different concentrations (o.10, 0.25, 0.50, and 1.00 M, see Figure S14).

The Tafel slope remained unchanged at about $60 \mathrm{mV} \mathrm{dec}^{-1}$ in the KOD solutions (Table $\mathrm{S}_{5}$, Figure $\mathrm{S}_{15} \mathrm{a}$ ), indicating no change in the OER mechanism. The potential required to reach $1 \mathrm{~mA} \mathrm{~cm} \mathrm{~cm}^{-2}$ (vs. RHE or RDE) shifted positively by about $30 \mathrm{mV}$ in all KOD solutions compared to in $\mathrm{KOH}$ solutions (Figure $7 \mathrm{a}$ ). Similarly, the $\mathrm{E}_{\mathrm{pc}}$ of the $\mathrm{Co}$ (III) to $\mathrm{Co}(\mathrm{IV})$ couple (Figure S15) shifted positively by about 31 $\mathrm{mV}$ in all KOD solutions compared to in $\mathrm{KOH}$ solutions (Figure $7 \mathrm{~b}$ ). Similar shifts were observed by Dau and coworkers on amorphous Co oxide films in neutral $\mathrm{pH} .{ }^{10}$ They attributed the shifts to an equilibrium isotope effect (EIE), which affected the redox potential of the Co(III) to Co(IV) couple. Their DFT computations predicted a shift of $33.3 \mathrm{mV}$ for the EIE. Thus, the Co(III) to Co(IV) oxidation $\left(\mathrm{CoOOH}\right.$ to $\left.\mathrm{CoO}_{2}\right)$ is responsible for the EIE observed in our study. The kinetic isotope effect (KIE) was calculated by comparing the current densities in $\mathrm{KOH}$ and $\mathrm{KOD}$ at the same overpotentials (Figure $7 \mathrm{c}, \mathrm{d}$ ). A small KIE of about $1.03( \pm 0.02)-1.05( \pm 0.04)$ was obtained in both 1.0 and $0.1 \mathrm{M}$ Fe-free KOH.

\section{Discussion}

3.1 Resting state of catalyst. Taking together our electrochemical, XAS, and Raman data indicate the dominance of a $\mathrm{Co}(\mathrm{IV})$ phase, commonly denoted as $\mathrm{CoO}_{2}$, under OER conditions. This $\mathrm{CoO}_{2}$ starts to form from $\mathrm{CoOOH}(1.35 \mathrm{~V})$ even before the onset of OER $(1.45 \mathrm{~V})$. Thus, the resting state of $\mathrm{CoOOH}$ under OER is $\mathrm{CoO}_{2}$. This finding is consistent with several previous reports. For example, $\mathrm{Co}(\mathrm{IV})=\mathrm{O}$ sites on $\mathrm{Co}_{3} \mathrm{O}_{4}$ were detected during photocatalytic OER by fast-scan FTIR. ${ }^{12} \mathrm{Co}(\mathrm{IV})$ species were also detected during electrocatalysis by electron paramagnetic resonance spectroscopy (EPR) for amorphous $\mathrm{CoO}_{\mathrm{x}}$ in a wide $\mathrm{pH}$ range ${ }^{49}$ and for Co-Pi films in neutral $\mathrm{pH}^{60} \mathrm{XAS}$ data also revealed a higher than (III) oxidation state for Co$\mathrm{Pi}^{61}$ and $\mathrm{CoOOH}$ nanosheets. ${ }^{31}$ There are also reports, where $\mathrm{CoOOH}$ but not $\mathrm{CoO}_{2}$ was detected under OER conditions. The discrepancy might be attributed to a different form of Co oxide (spinel versus $\mathrm{CoOOH}),{ }^{47}$ or a thick film where the bulk might be largely inactive. ${ }^{62}$ While the dominating resting state is $\mathrm{Co}(\mathrm{IV})$, the XAS data suggest that other phases which contain Co(III) ions might be present as well. 
(a)

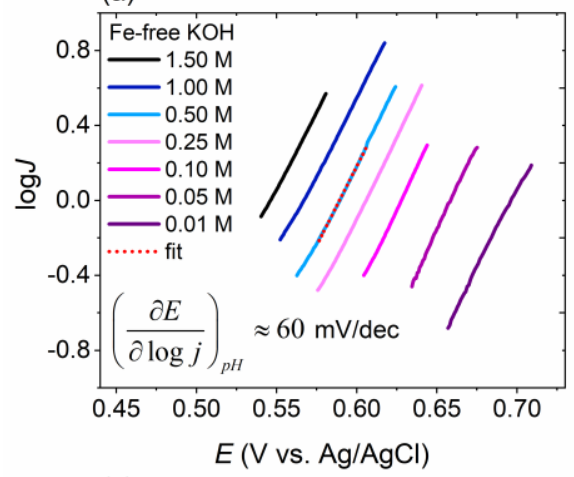

(c)

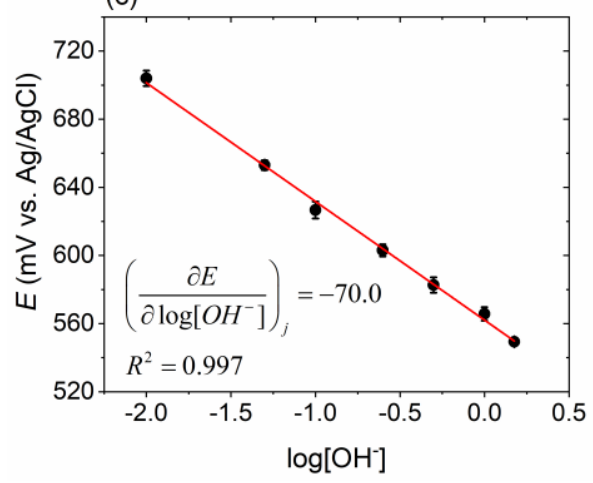

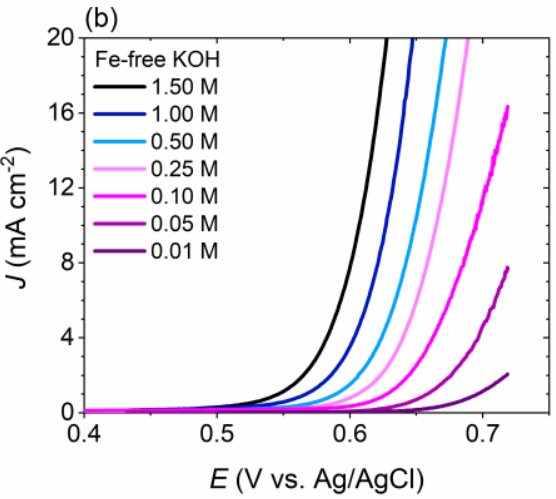

(d)

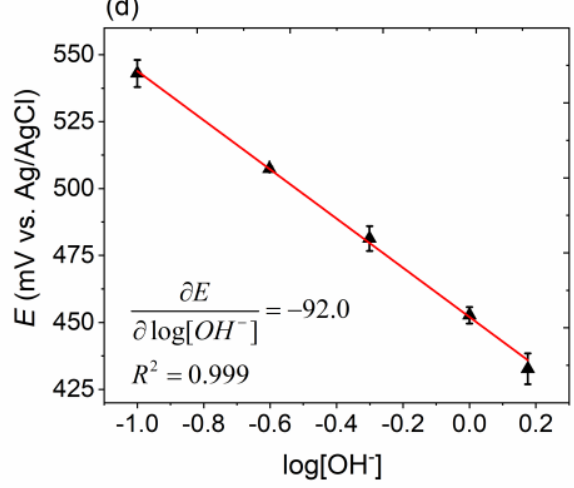

Figure 6. (a) Tafel plots at various pHs, (b) Electrochemical activity in Fe-free $\mathrm{KOH}$ solutions of various concentrations (1.50, 1.00, 0.50, 0.25, 0.10, 0.05, 0.01 M), (c) Fitting plot of the potentials at $1 \mathrm{~mA} \mathrm{~cm}^{-2}$ versus the logarithm of [OH'], (d) Fitting plot of the reduction potential $E_{\mathrm{pc}}(\mathrm{Co}(\mathrm{IV}) / \mathrm{Co}(\mathrm{III}))$ versus the logarithm of $\left[\mathrm{OH}^{-}\right]$. Due to the change of pHs, the reference potentials were chosen as $\mathrm{Ag} / \mathrm{AgCl}\left(E^{\circ}(\mathrm{Ag} / \mathrm{AgCl})=+0.197 \mathrm{~V}\right.$ vs. NHE$)$.

3.2 Lattice oxygen isotope exchange. The results from oxygen isotope labelling experiments (Figures $4,5 \mathrm{~b}$ ) indicate that for $\mathrm{CoOOH}$, the lattice oxygen can rapidly exchange with the electrolyte at potentials lower than that of OER. The exchange might occur via a dissociative mechanism where a lattice $\mathrm{O}$ atom first moves to an $\mathrm{O}$ vacancy site to liberate a binding site for the $\mathrm{O}$ atom from the $\mathrm{OH}^{-}$ electrolyte. Alternatively, the exchange might occur via an associative mechanism. For $\mathrm{CoO}_{2}$, the lattice $\mathrm{O}$ atom can only exchange with the electrolyte via OER. This exchange, in turn, indicates the participation of lattice oxygen in OER, which has now been reported in a number of systems. ${ }^{30,31,42,63}$ 

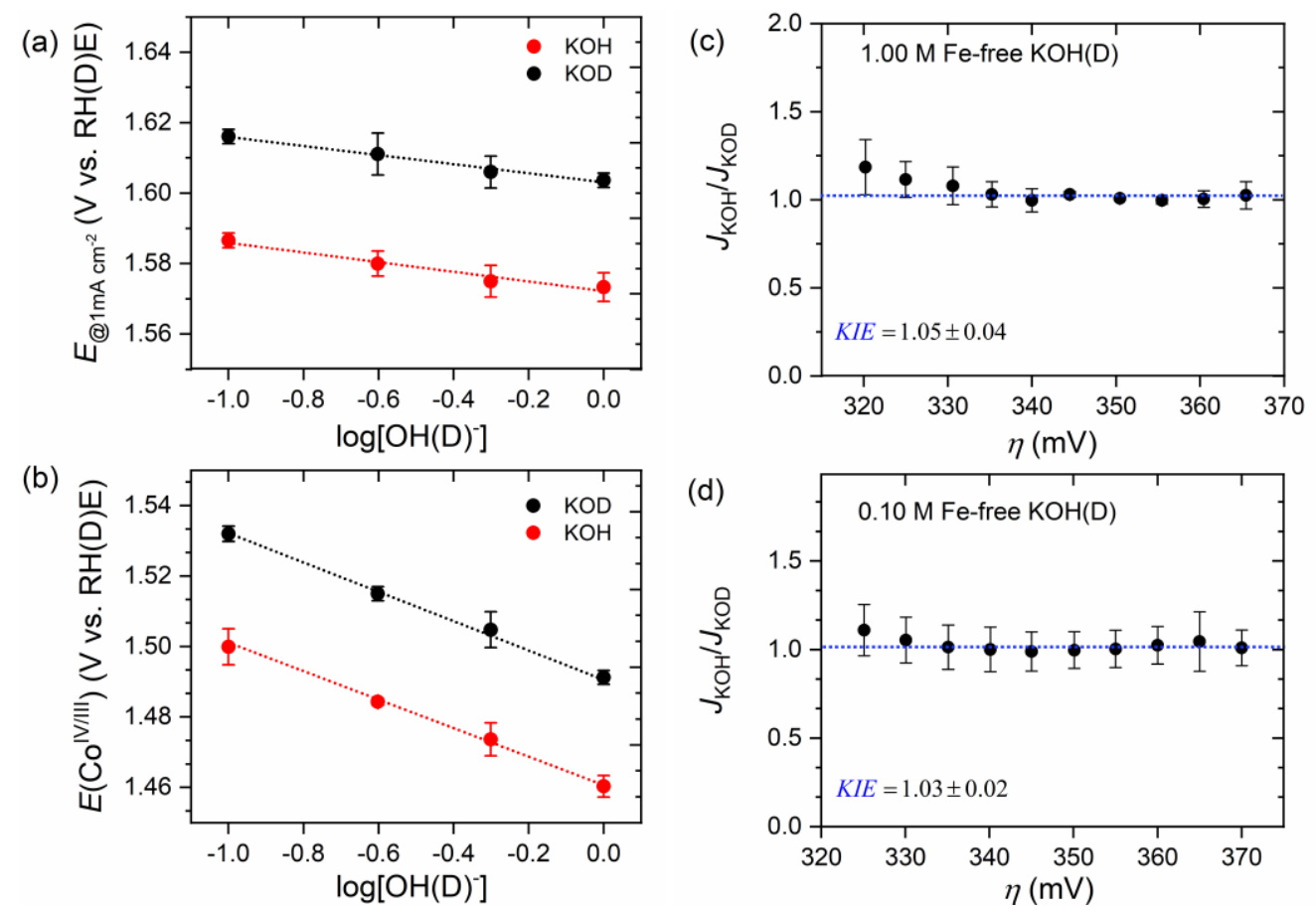

Figure 7. (a) Plots of potential (V vs. RHE and RDE) at $1 \mathrm{~mA} \mathrm{~cm}{ }^{-2}$ versus the logarithm of $\left[\mathrm{OH}^{-}\right]$or [OD-] in Fe-free $\mathrm{KOH}$ and Fe-free KOD, respectively. (b) Plots of redox potential of the $\mathrm{Co}(\mathrm{III}) / \mathrm{Co}(\mathrm{IV})$ couple $\left(\mathrm{E}_{\mathrm{pc}}\right.$ ) versus the logarithm of $\left[\mathrm{OH}^{-}\right]$ or $\left[\mathrm{OD}^{-}\right]$in Fe-free $\mathrm{KOH}$ and Fe-free KOD, respectively. The values are the means of three different samples; error bar designates standard deviation. Determination of kinetic isotope effect (KIE) by comparing the current densities in $\mathrm{KOH}$ and KOD at same overpotentials in (c) $1.0 \mathrm{M}$ and (d) $0.10 \mathrm{M}$ electrolyte solutions.

3.3 Superoxide intermediate. In situ Raman data (Figures za, S9) reveal the presence of an active oxygen species, and isotope labelling experiments (Figures $3 \mathrm{~b}-5$ ) confirm this species as a superoxide. The superoxide species is formed at the same time as the oxidation of $\mathrm{CoOOH}$ to $\mathrm{CoO}_{2}$, which occurs before the onset of OER. Moreover, both $\mathrm{O}$ atoms of the superoxide moiety can exchange with the $\mathrm{O}$ atoms of $\mathrm{OH}^{-}$electrolyte. The exchange takes place either via lattice $\mathrm{O}$ exchange before OER as in $\mathrm{CoOOH}$ or via OER as in $\mathrm{CoO}_{2}$. Thus, the superoxide species is a precursor to dioxygen.

Our results indicate that $\mathrm{O}-\mathrm{O}$ bond formation occurs before the rate-determining step OER, which contradicts most current mechanistic proposals. ${ }^{6,10,14,49}$ Gold and nickel oxides, however, were reported to have peroxo or superoxo species formed before OER.41,42,64 Because lattice O participates in OER, at least one of the $\mathrm{O}$ atoms in the superoxide moiety comes from lattice $\mathrm{O}$. Two possibilities exist for the formation of the superoxide: ${ }^{12,65}$ nucleophilic attack of an $\mathrm{OH}^{-}$from the electrolyte or in the catalyst on a lattice $\mathrm{O}$ followed by concerted oxidation and deprotonation, or combination of two lattice $\mathrm{O}$ atoms. The deuterium-EIE and -KIE values obtained in our study (Figures 7c, d) suggest that the hydroperoxide pathway is unlikely. Otherwise, the transformation of hydroperoxide to superoxide species would contribute to either the EIE or KIE. The latter pathway has precedents in lithium-ion batteries, $23,24,66-$ ${ }^{68}$ where anion redox chemistry leads to $2\left(\mathrm{O}^{2-}\right) /\left(\mathrm{O}_{2}\right)^{\mathrm{n}-}$ conversion. The reversibility of this reaction depends on the interaction of the $\left(\mathrm{O}_{2}\right)^{\mathrm{n}-\mathrm{s}}$ species with the metal ions. A strong covalent bond can stabilize $\left(\mathrm{O}_{2}\right)^{\mathrm{n}-}$, increasing the battery's capacity. ${ }^{69} \mathrm{~A}$ weak bond facilitates the evolution of $\mathrm{O}_{2}$ from $\left(\mathrm{O}_{2}\right)^{\mathrm{n}-}{ }^{69}$ The involvement of $\mathrm{O}$ redox in OER was already invoked for Co oxyhydroxides, where the onset of the catalytic OER was coupled to a formal $\mathrm{Co}(\mathrm{III}) / \mathrm{Co}(\mathrm{IV})$ redox transition, as well as oxidized $\mathrm{Co}^{+3+\delta}$ ions bound to terminal $\mathrm{O}^{-(2-\mathrm{d})}$ ligands. ${ }^{8}$ Likewise, a recent study suggests the active species of delithiated $\mathrm{Li}_{2} \mathrm{Co}_{2} \mathrm{O}_{4}$ in OER has a $\mathrm{Co}(\mathrm{IV})-\mathrm{O}$ moiety where the $\mathrm{O}$ ion is oxidized. $7^{\circ}$

The mechanism of the formation of Co-superoxide species in this study differs from that of the Co-superoxide intermediate in photocatalytic OER in near-neutral solutions catalyzed by $\mathrm{Co}_{3} \mathrm{O}_{4}{ }^{12}$ The latter intermediate was proposed to form by nucleophilic addition of $\mathrm{H}_{2} \mathrm{O}$ to a dimeric $\mathrm{O}=\mathrm{Co}(\mathrm{IV})(\mathrm{m}-\mathrm{O})_{2} \mathrm{Co}(\mathrm{IV})=\mathrm{O}$ to give a hydroperoxide-Co species followed by $1 \mathrm{e}^{-}$oxidation. The two systems actually exhibit notable differences in properties and reactivity. Our $\mathrm{CoOOH}$ readily exchanges lattice $\mathrm{O}$ with $\mathrm{OH}^{-}$electrolyte while the $\mathrm{Co}_{3} \mathrm{O}_{4}$ system did not; our system does not involve a hydroperoxide intermediate while the $\mathrm{Co}_{3} \mathrm{O}_{4}$ system did. These differences might arise from the different external inputs (photo vs. electro), forms of catalysts $\left(\mathrm{Co}_{3} \mathrm{O}_{4}\right.$ versus $\left.\mathrm{CoOOH}\right)$, or reaction media (near neutral vs. alkaline) employed in the two studies. 


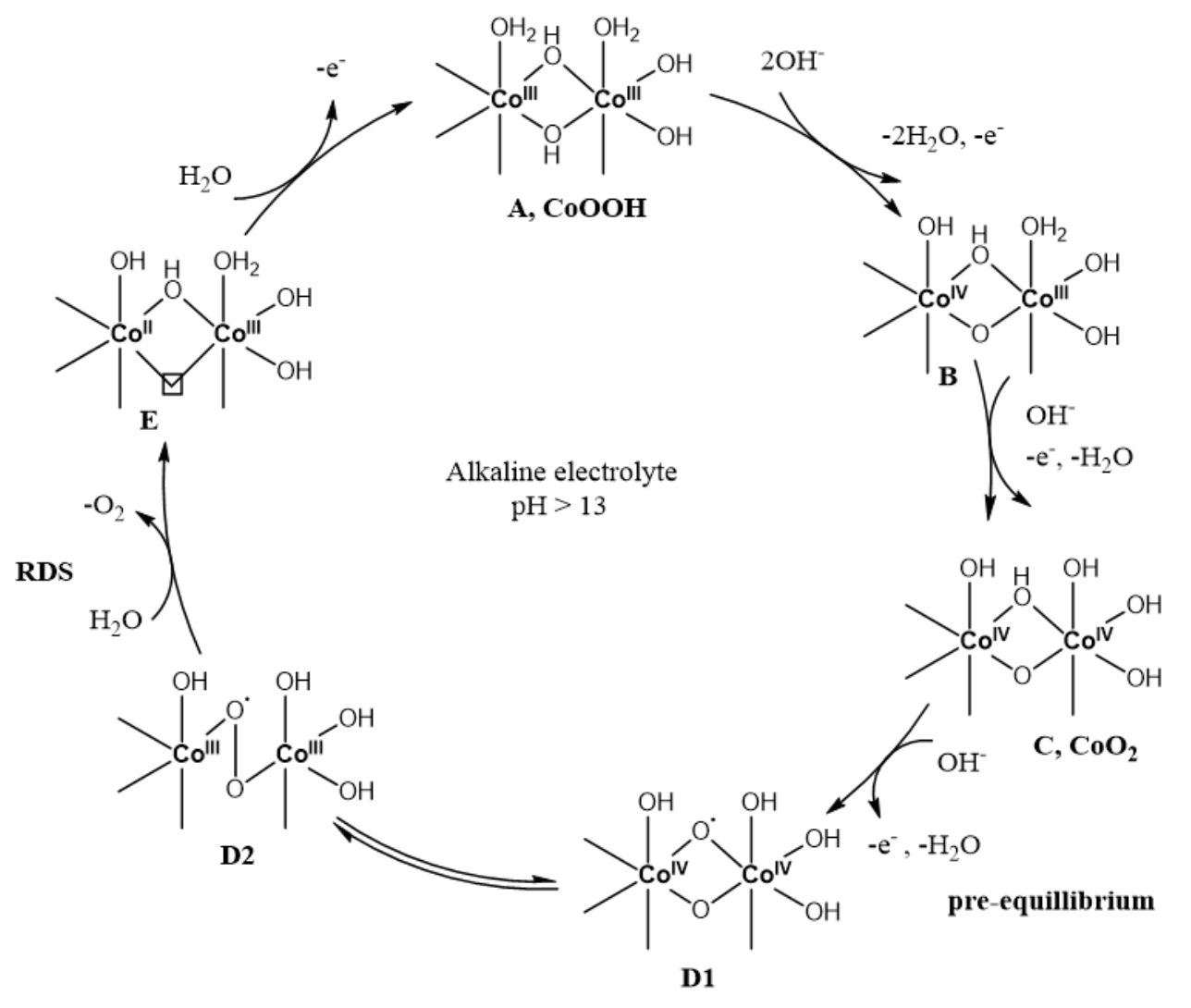

Figure 8. Proposed OER mechanism.

3.4 Mechanism of OER. An OER mechanism that is consistent with our spectroscopic and electrokinetic data is proposed in Figure 8 (see SI for details of the electrokinetic model). The super-Nernstian behavior of the Co(III) to $\mathrm{Co}(\mathrm{IV})$ oxidation can be reconciled by considering a di-Co active site, where the oxidation of the first $\mathrm{Co}(\mathrm{III})$ ion is accompanied by a loss of 2 protons (A to $\mathrm{B}$ ) and the oxidation of the second $\mathrm{Co}(\mathrm{III})$ ion is accompanied by a loss of 1 proton (B to C). In a proton coupled electron transfer step, deprotonation and oxidation of the resting state $\mathrm{CoO}_{2}$ by 1-electron occurs at the $\mathrm{O}$ anion to give a $\mathrm{Co}(\mathrm{IV})-\mathrm{O} \cdot$ species ( $C$ to $\mathrm{D} 1)$. We propose this species is in equilibrium to a bridging Co-superoxide-Co species $\mathrm{D} 2$, which is the active oxygen species observed in the Raman spectra. The oxidation of $C$ to $D_{1} / D_{2}$ is considered as a pre-equilibrium. The rate-determining step is then release of $\mathrm{O}_{2}$ from $\mathrm{D}_{2}$ with a concomitant $\mathrm{H}_{2} \mathrm{O}$ binding (D2 to E). Binding of another $\mathrm{H}_{2} \mathrm{O}$ and a further 1e oxidation then regenerates the starting $\mathrm{Co}$ (III) form of the catalyst $(\mathrm{CoOOH})$. This sequence would give a Tafel slope, a first order in $\left[\mathrm{OH}^{-}\right]$, as well as D-EIE and -KIE that agree with experimental values. The mechanism predicts that the concentration of the superoxide species would increase with increasing potentials, which was also observed (Fig. S9b, SI). Given the observation of both $\mathrm{CoO}_{2}$ and $\mathrm{Co}^{-} \mathrm{OO}^{-}$species ( $\mathrm{C}$ and $\left.\mathrm{D}_{2}\right)$ before the onset of OER, we propose the potential-determining step is the oxidation of the second $\mathrm{Co}$ (III) to $\mathrm{Co}$ (IV) (B to C).

While previous studies mostly invoke $\mathrm{Co}(\mathrm{IV})=\mathrm{O}$ or $\mathrm{Co}(\mathrm{III})-\mathrm{O} \cdot$ as the highest valent $\mathrm{Co}$ species responsible for
$\mathrm{O}-\mathrm{O}$ bond formation, ${ }^{10,12,14,49}$ a $\mathrm{Co}(\mathrm{IV})-\mathrm{O}$. intermediate is most consistent with our spectroscopic and electrokinetic data. Such an intermediate is also proposed by previous experimental ${ }^{71}$ and theoretical studies, ${ }^{72,73}$ which show that the formation of $\mathrm{Co}(\mathrm{IV})-\mathrm{O}$. is necessary for $\mathrm{O}-\mathrm{O}$ bond formation catalyzed by various small Co-oxides fragments. A theoretical study suggested that assuming 4 consecutive PCET as the mechanism of OER, the most active site of crystalline $\beta$-CoOOH has a resting state of $\mathrm{Co}$ (III) instead of Co(IV). ${ }^{74}$ Such a mechanism would not apply to our system as our electrokinetic data cannot be fit by 4 PCETs.

Even though dioxygen release as a rate-determining step in OER has not been proposed for Co-based catalysts, it does have several precedents in other types of catalysts. For example, water oxidation by some Ru-based molecular catalysts was shown to be kinetically governed by the liberation of dioxygen from $\mathrm{Ru}(\mathrm{IV})$ species. ${ }^{75,76}$ Moreover, it was reported that on $\mathrm{Ni}$ oxide there is a slow OER cycle that involves dioxygen releases as a rate-determining step. ${ }^{43}$ Finally a theoretical study simulating different active sites of $\mathrm{Co}_{3} \mathrm{O}_{4}$ surface reported that the kinetics of water addition and dioxygen release steps might determine the rate of the reaction in lower potential regions at certain sites. 77

We compare our mechanism to representative mechanisms previously proposed for Co-based catalysts. First we compare among amorphous Co oxides and oxyhydroxides $\left(\mathrm{CoO}_{x}\right.$ and $\left.\mathrm{CoOOH}\right)$, which likely have similar active sites. Gerken et al. ${ }^{49}$ proposed that for electrodeposited $\mathrm{CoO}_{x}$ at $\mathrm{pH}_{3.5}-14$ the resting state was a mixed-valent $(\mathrm{OH}) \mathrm{Co}(\mathrm{III})$ - 
$(\mu-\mathrm{O})_{2}-\mathrm{Co}(\mathrm{IV})=\mathrm{O}$ species, which was in pre-equilibrium with a $\mathrm{CoO}_{2}$-type species $\mathrm{O}=\mathrm{Co}(\mathrm{IV})-(\mu-\mathrm{O})_{2}-\mathrm{Co}(\mathrm{IV})=\mathrm{O}$ via a PCET. The RDS is the attack of a hydroxide to the $\mathrm{CoO}_{2}$ species to give a $(\mathrm{OH}) \mathrm{Co}(\mathrm{III})-(\mu-\mathrm{O})_{2}-\mathrm{Co}(\mathrm{III})-\mathrm{OOH}$, which upon two further PCET releases $\mathrm{O}_{2}$ and yields a $\mathrm{Co}$ (III) species $(\mathrm{OH}) \mathrm{Co}(\mathrm{III})-(\mu-\mathrm{O})_{2}-\mathrm{Co}(\mathrm{III})-\mathrm{OH}$. The latter undergoes a PCET to regenerate the resting state. A similar mechanism was proposed for $\mathrm{CoPi}$ catalyst in near neutral $\mathrm{pH}$, except that the $\mathrm{O}-\mathrm{O}$ bond forming step was coupling of two oxo species. ${ }^{10,11,14}$ This mechanism features a similar active site, but a different resting state and RDS, to our present mechanism. Notably, like the present work, Gerken et al. revealed a Tafel slope of $60 \mathrm{mV} \mathrm{dec^{-1 }}$ and the presence of $\mathrm{Co}$ (IV)-containing resting species before OER. However, they reconciled these findings by proposing a mixed $\mathrm{Co}(\mathrm{III})-\mathrm{Co}$ (IV) resting state which would be oxidized via PCET to a more active $\mathrm{Co}(\mathrm{IV})-\mathrm{Co}(\mathrm{IV})$. Nucleophilic attack of $\mathrm{OH}^{-}$on a $\mathrm{Co}(\mathrm{IV})=\mathrm{O}$ moiety of the latter led to $\mathrm{O}-\mathrm{O}$ bond formation, which was proposed as the RDS. This mechanism is not consistent with our data, especially the observation of the superoxide intermediate. On the other hand, the data in the study of Gerken et al. can be reconciled by our mechanism, pointing to a need for additional experimental probes such as the in situ Raman and full kinetic study described here to differentiate multiple mechanisms.

We then compare our mechanism to those proposed for crystalline $\mathrm{Co}_{3} \mathrm{O}_{4}$, which has a different structure than $\mathrm{CoOOH}$. In particular $\mathrm{Co}_{3} \mathrm{O}_{4}$ has both tetrahedrally (Td) and octahedrally $(\mathrm{Oh})$ coordinated $\mathrm{Co}$ ions whereas $\mathrm{CoOOH}$ has only Oh Co sites. ${ }^{8}$ It has been shown that under electrocatalytic conditions, $\mathrm{Co}_{3} \mathrm{O}_{4}$ would be converted into $\mathrm{CoOOH}$, which was the active phase for OER. $8,78-80$ For photocatalytic OER on $\mathrm{Co}_{3} \mathrm{O}_{4}$, Frei and co-workers proposed a similar active di-Co site ${ }^{12}$ as those of $\mathrm{CoOOH}$. Two consecutive oxidation of $(\mathrm{OH}) \mathrm{Co}(\mathrm{III})-(\mu-\mathrm{O})_{2}-\mathrm{Co}(\mathrm{III})-\mathrm{OH}$ via $\mathrm{PCET}$ gives $\mathrm{O}=\mathrm{Co}(\mathrm{IV})-(\mu-\mathrm{O})_{2}-\mathrm{Co}(\mathrm{IV})=\mathrm{O}$. Nucleophilic attack of water on the $\mathrm{Co}(\mathrm{IV})=\mathrm{O}$ unit then yields a $(\mathrm{OH}) \mathrm{Co}(\mathrm{III})-(\mu-\mathrm{O})_{2}-\mathrm{Co}(\mathrm{III})-\mathrm{OOH}$, which undergoes a further PCET to give a superoxide species $(\mathrm{OH}) \mathrm{Co}(\mathrm{III})-(\mu-$ $\mathrm{O})_{2}-\mathrm{Co}(\mathrm{III})-\mathrm{OO}$. This superoxide intermediate was detected by infrared (IR) spectroscopy, which also indicated that the superoxide is involved in hydrogen bonding with the neighboring $\mathrm{HO}-\mathrm{Co}$ unit. Oxidation of the superoxide in a fourth PCET event leads to $\mathrm{O}_{2}$ release and the regeneration of the di-Co(III) species. This step is the RDS. This mechanism was supported by spectroscopic data. Both this and our mechanisms feature $\mathrm{O}-\mathrm{O}$ bond formation before the RDS. The main differences between the two mechanisms are the $\mathrm{O}-\mathrm{O}$ bond forming and $\mathrm{O}_{2}$ release steps. As mentioned in section 3.3, the differences may have originated from different materials, different $\mathrm{pHs}$ (neutral vs. alkaline), and different oxidation conditions (pulse laser vs. continuous electrochemical potential). These differences also suggest a mechanistic diversity among OER catalysts.

\section{Conclusion}

A comprehensive electrochemical and spectroscopic study of $\mathrm{CoOOH}$, an archetypical OER catalyst in alkaline medium, was conducted. The dominating resting state of the catalyst under OER conditions is a Co(IV) species, termed $\mathrm{CoO}_{2}$. The $\mathrm{Co}(\mathrm{IV})$ species seems to co-exist with minor $\mathrm{Co}(\mathrm{III})$ or $\mathrm{Co}(\mathrm{III} / \mathrm{IV})$ species. Notably, a Co-superoxide intermediate is identified by Raman spectroscopy. The chemical nature of the Co-peroxide as well as its participation in OER is established unequivocally by oxygen isotope exchange experiments. The Co-superoxide intermediate is formed upon transformation of $\mathrm{CoOOH}$ to $\mathrm{CoO}_{2}$, before the rate-determining step. Based on spectroscopic and electrokinetic data, the mechanism of OER by $\mathrm{CoOOH}$ is proposed to involve the combination of two lattice $\mathrm{O}$ atoms to form the Co-superoxide intermediate and the release of dioxygen from the Co-superoxide intermediate as the rate-determining step. This study provides new mechanistic insights in OER, possibly provoking a re-evaluation of commonly assumed mechanisms.

\section{Experimental Methods}

Film preparation. Thin films of cobalt (oxy)hydroxide were prepared by galvanostatic electrodeposition applying an anodic current of $10 \mu \mathrm{A}$ for $3 \min \left(51 \mu \mathrm{A} \mathrm{cm} \mathrm{cm}^{-2}\right)$, unless otherwise stated. The deposition bath comprised o.o1 $\mathrm{M}$ cobalt nitrate $\left(\mathrm{Co}\left(\mathrm{NO}_{3}\right)_{2} \cdot 6 \mathrm{H}_{2} \mathrm{O}, \geq 98 \%\right.$, Sigma-Aldrich) in o.1 $\mathrm{M}$ sodium acetate $\left(\mathrm{NaCH}_{3} \mathrm{CO}_{2}\right.$, anhydrous, $\geq 99 \%$, Sigma-Aldrich) as supporting electrolyte. Milli-pore water $(18.2 \mathrm{M} \Omega \mathrm{cm})$ and analytical grade reagents were employed.

Preparation of Fe-free KOH. The electrolyte $(1 \mathrm{~N} \mathrm{KOH}$ standard solution, Merck KGaA, diluted with $18.2 \mathrm{M} \Omega \mathrm{cm}$ $\mathrm{H}_{2} \mathrm{O}$ ) was purified using high purity cobalt nitrate salts following a reported procedure..$^{25,81}$ 0.5-1.0 g of $\mathrm{Co}\left(\mathrm{NO}_{3}\right)_{2} \cdot 6 \mathrm{H}_{2} \mathrm{O}$ were dissolved in $5 \mathrm{~mL}$ of ultrapure water, which was added to $20 \mathrm{~mL}$ of $0.1 \mathrm{M} \mathrm{KOH}$. The resulted $\mathrm{Co}(\mathrm{OH})_{2}$ precipitate was centrifuged and washed three times with ultrapure water. Next, the $\mathrm{Co}(\mathrm{OH})_{2}$ precipitate was suspended in $50 \mathrm{~mL}$ of $1.0 \mathrm{M} \mathrm{KOH}$, and the mixture was mechanically agitated overnight to absorb the Fe impurities. For the ${ }^{18} \mathrm{O}$ experiments, $0.10 \mathrm{M}{ }^{18} \mathrm{O}-\mathrm{KOH}$ was prepared using ${ }^{18} \mathrm{O}$-water with a $97 \%$ isotopic purity $\left(\mathrm{H}_{2}{ }^{18} \mathrm{O}\right.$, $97 \%$ atom ${ }^{18} \mathrm{O}$, Sigma-Aldrich) and pellets of potassium hydroxide ( $\mathrm{KOH}, \geq 85 \%$, Sigma-Aldrich). Fe ions were removed from the as prepared $0.1 \mathrm{M}^{18} \mathrm{O}-\mathrm{KOH}$ using the same method.

Electrochemical tests. For electrochemical measurements, we used a three-electrode setup comprising an $\mathrm{Au} /$ carbon cloth substrate as working electrode, a Pt-wire counter electrode, and a custom-made double-junction $\mathrm{Ag} / \mathrm{AgCl}$ in a saturated $\mathrm{KCl}$ solution reference electrode in a Teflon cell. Clean Pt surfaces were obtained by dipping the wire in aqua regia for a few seconds, rinsing it with copious amounts of water, and annealing it with gas $-\mathrm{O}_{2}$ flame. All experiments were carried out in Fe-free solutions. CV and electrokinetic tests were done on samples deposited on carbon cloth; Raman and EIS were done on samples deposited on Au. 
Electrochemical surface area. The ECSA of the cobalt oxyhydroxide on Au was calculated using both cyclic voltammetry and electrochemical impedance spectroscopy (EIS). For the cyclic voltammetry, the electrode potential was cycled from $1.255 \mathrm{~V}$ to $1.345 \mathrm{~V}$ vs. RHE at different scan rates $\left(10,20,50,100,150,200 \mathrm{mV} \mathrm{s}^{-1}\right)$, where we observed only the capacitive behavior of the films, not redox events. The double-layer capacitance, $C_{d l}$, is calculated according to equation 4 , where $j_{a}$ and $j_{c}$ are the anodic and cathodic current densities, respectively, and $v$ is the scan rate. Once the $C_{d l}$ is calculated at $1.30 \mathrm{~V}$ vs. RHE, the ECSA is determined by dividing the $C_{\mathrm{dl}}$ with the specific capacitance, $C_{s}$, (equation 5), assuming a specific capacitance of $40 \mu \mathrm{F} \mathrm{cm}$ ${ }^{2} .{ }^{19}$ For the specific capacitance, a value of $40 \mu \mathrm{F} \mathrm{cm}^{-2}$ in 1 $\mathrm{M} \mathrm{NaOH}$ for this type of materials has been used in the literature, although variations might be expected..$^{82-84}$ The geometric surface area of the electrode used in these measurements is $0.1926 \mathrm{~cm}^{2}$. The roughness factor was determined by dividing ECSA with the geometric area.

$C_{d l}=\frac{\left|j_{a}-j_{c}\right|}{2 v}$

$E C S A=\frac{C_{d l}}{C_{S}}$

The impedance of the films was measured in a frequency range from $10 \mathrm{kHz}$ to $0.1 \mathrm{~Hz}$. The amplitude of the applied alternating potential was $10 \mathrm{mV}$. The EIS response was recorded at OCP and potentials from 1.15 V to $1.75 \mathrm{~V}$ vs. RHE. Before the EIS measurement, the electrode was set to stabilize for $30 \mathrm{~s}$ at each respective potential. We analyzed and fitted the impedance data using Zview software. Based on the values of the double-layer capacitance, $C_{d l}$, we calculated the ECSA at different potentials for each catalyst, according to equation 5 .

For the ECSA of Au, we performed cyclic voltammetry in o.1 M phosphate buffer solutions ( $\mathrm{pH} 7.4$ ) between the potential values of 0.5 and $1.9 \mathrm{~V}$ vs. RHE with a scan rate of 50 $\mathrm{mV} \mathrm{s}^{-1} .85$ The actual surface area is equal to the stripping charge of the oxide, $Q_{\text {AuO }}(\mu \mathrm{C})$, divided by $482 \mu \mathrm{C} \mathrm{cm}^{-2}$, the theoretical mean surface concentration of gold atoms on a flat surface. ${ }^{86}$ The stripping charge is calculated by integrating the reduction peak of the gold oxide appearing in the cathodic scan.

In situ surface enhanced Raman spectroscopy. In situ Raman experiments were performed in a single-compartment, three-electrode, custom-made electrochemical Teflon cell at room temperature. A 63x water-immersed objective (Leica-Microsystems) was coupled with the Raman microscope (in Via Raman microscope, Renishaw). The wavenumber of the excitation light source was $785 \mathrm{~nm}$, with a laser power of $\sim 1 \%$ at the grading of $1200 \mathrm{l} \mathrm{mm}^{-1}$. Twenty consecutive scans, with $3 \mathrm{~s}$ exposure time per scan, produced each spectrum with a resolution of $1 \mathrm{~cm}^{-1}$. To ensure high confidence and reproducibility in the quality of the obtained spectra, we calibrated the energy shift using the $520 \pm 0.5 \mathrm{~cm}^{-1}$ peak of silicon. We roughened the gold supports to obtain the surface-enhanced effect. ${ }^{18,44}$ After mechanically polishing with $0.1-0.3 \mu \mathrm{m}$ alumina powder, the Au substrates were sonicated twice in 1:1 mixture of ethanol and acetone and twice in ultrapure water for 10 min. Before the electrochemical roughening procedure ${ }^{18}$, the clean Au substrates were dipped in concentrated sulfuric acid solution and washed with ultrapure water to mitigate cross-contamination between different experiments. We performed potential cycling between $-0.28 \mathrm{~V}$ and 1.22 $\mathrm{V}$ vs. $\mathrm{Ag} / \mathrm{AgCl}$ while letting the potential to rest for 10 and $5 \mathrm{~s}$ at the lower and upper limits, respectively. The cycling was followed by a 5 min chronoamperometry at $-0.3 \mathrm{~V}$ vs. $\mathrm{Ag} / \mathrm{AgCl}$. The dark-brown roughened Au surfaces proved to be critical for the SERS experiments and affected the deconvolution and detection of Raman peaks. The counter electrode was a platinum wire, and the reference electrode was a custom-made double-junction $\mathrm{Ag} / \mathrm{AgCl}$ electrode in a saturated $\mathrm{KCl}$ solution $\left(+0.197 \mathrm{~V}\right.$ vs. NHE at $\left.25^{\circ} \mathrm{C}\right)$. The Raman signals were recorded in situ at OCP and under different applied potentials spanning from 1.15 to $1.75 \mathrm{~V}$ vs. RHE. In all SERS experiments, the electrolyte was o.1o M Fe-free $\mathrm{KOH}$ in order to mitigate the bubble generation under OER potentials.

Characterization methods. ICP-OES analyses were performed on as-deposited samples by a Nexlon 350 (Perkin Elmer) machine. The samples were digested in $65 \% \mathrm{HNO}_{3}$ (Merck) and diluted in water to reach a final concentration of $2 \% \mathrm{w} / \mathrm{w} \mathrm{HNO}_{3}$. Three samples were analyzed to give averaged results.

Scanning Electron Microscopy (SEM). Surface characterization was performed with a Gemini field-emission scanning electron microscope. A 1-3 kV accelerating voltage was chosen for the analysis. Secondary electrons were collected with an in-lens detector, and the surfaces were imaged directly with no further treatment. The thickness of the films was measured by viewing a cross-section of the catalyst deposited on a flat FTO/glass substrate. The roughened gold substrates were also characterized.

X-ray Photoelectron Spectroscopy (XPS). X-ray photoelectron spectroscopy analyses were carried out using a PHI VersaProbe II scanning XPS microprobe (Physical Instruments AG, Germany). An Al Ka source with a power of $24.8 \mathrm{~W}$ and a beam size of $100 \mu \mathrm{m}$ generated the monochromatic X-rays. The spherical capacitor analyzer was set at a $45^{\circ}$ take-off angle with respect to the sample surface. The pass energy was $46.95 \mathrm{eV}$ yielding a full width at half maximum of $0.91 \mathrm{eV}$ for the $\mathrm{Ag} 3 \mathrm{~d}$ 5/2 peak. The adventitious carbon is peak was calibrated at $284.8 \mathrm{eV}$ and used as an internal standard. XPS data analysis was performed using the PHI MultiPak software.

X-ray Absorption Spectroscopy (XAS). The XAS data were collected in fluorescence mode, which recorded at beamline $12 \mathrm{~B}$ in Spring- 8 of Taiwan beamline of the $\mathrm{Na}$ tional Synchrotron Radiation Research Center (NSRRC). Samples were deposited on a carbon cloth substrate (12000 $\mu \mathrm{c} / \mathrm{cm}_{2}$ ). The electron storage ring was operated at $8.0 \mathrm{GeV}$ with a constant current of $\sim 100 \mathrm{~mA}$. The incident beam energy was monochromatized using a $\mathrm{Si}$ (111) double crystal monochromator. The scan range was kept in an energy 
range of $7600-8500 \mathrm{eV}$ for Co K-edge. The data collected were normalized to the incoming incident photon flux and processed with the Athena software from the IFEFFIT package. $E_{o}$ values of $7709.0 \mathrm{eV}$ were used to calibrate all data with respect to the first inflection point of the absorption K-edge of iron foil. Extended X-Ray Absorption Fine Structure (EXAFS) analysis was conducted using Fourier transform on $\mathrm{k}^{3}$-weighted EXAFS oscillations to evaluate the contribution of each bond pair to Fourier transform peak.

\section{ASSOCIATED CONTENT}

Supporting Information. This material is available free of charge via the Internet at http://pubs.acs.org."

\section{AUTHOR INFORMATION}

\section{Corresponding Author}

*xile.hu@epfl.ch

\section{Author Contributions}

†A.M and S.L contributed equally.

\section{Funding Sources}

This project has received funding from the European Research Council (no. 681292) and the Marie Skłodowska-Curie Fellowship (no. 838367) under the European Union's Horizon 2020 research and innovation program and from the Ministry of Science and Technology, Taiwan (Contract Nos. MOST 1082628-M-002-004-RSP).

\section{ACKNOWLEDGMENT}

We thank Dr. Natalia Gasilova (EPFL) for the ICP measurements and Dr. Pierre Mettraux (EPFL) for the X-ray Photoelectron Spectroscopy measurements.

\section{REFERENCES}

(1) Lewis, N. S.; Nocera, D. G. Powering the Planet: Chemical Challenges in Solar Energy Utilization. Proc. Natl. Acad. Sci. 2oo6, 103 (43), 15729-15735.

(2) Chu, S.; Majumdar, A. Opportunities and Challenges for a Sustainable Energy Future. Nature 2012, 488 (7411), 294-303.

(3) Lewis, N. S. Research Opportunities to Advance Solar Energy Utilization. Science 2016, 351 (6271), aadig2o.

(4) Hunter, B. M.; Gray, H. B.; Müller, A. M. Earth-Abundant Heterogeneous Water Oxidation Catalysts. Chem. Rev. 2016, 116 (22), 14120-14136.

(5) Song, F.; Bai, L.; Moysiadou, A.; Lee, S.; Hu, C.; Liardet, L.; $\mathrm{Hu}, \mathrm{X}$. Transition Metal Oxides as Electrocatalysts for the Oxygen Evolution Reaction in Alkaline Solutions: An Application-Inspired Renaissance. J. Am. Chem. Soc. 2018, 140 (25), 7748-7759.

(6) Suen, N.-T.; Hung, S.-F.; Quan, Q.; Zhang, N.; Xu, Y.-J.; Ming Chen, H. Electrocatalysis for the Oxygen Evolution Reaction: Recent Development and Future Perspectives. Chem. Soc. Rev. 2017, 46 (2), 337-365.

(7) Bockris, J. O. Kinetics of Activation Controlled Consecutive Electrochemical Reactions: Anodic Evolution of Oxygen. J. Chem. Phys. 1956, 24 (4), 817-827.

(8) Bergmann, A.; Jones, T. E.; Moreno, E. M.; Teschner, D.; Chernev, P.; Gliech, M.; Reier, T.; Dau, H.; Strasser, P. Unified Structural Motifs of the Catalytically Active State of Co(Oxyhydr)Oxides during the Electrochemical Oxygen Evolution Reaction. Nat. Catal. 2018, 1 (9), 711.
(9) Dau, H.; Limberg, C.; Reier, T.; Risch, M.; Roggan, S.; Strasser, P. The Mechanism of Water Oxidation: From Electrolysis via Homogeneous to Biological Catalysis. ChemCatChem 2010, 2 (7), 724-761.

(10) Pasquini, C.; Zaharieva, I.; González-Flores, D.; Chernev, P.; Mohammadi, M. R.; Guidoni, L.; Smith, R. D. L.; Dau, H. H/D Isotope Effects Reveal Factors Controlling Catalytic Activity in Co-Based Oxides for Water Oxidation. J. Am. Chem. Soc. 2019, 141 (7), 2938-2948.

(11) Wang, L.-P.; Van Voorhis, T. Direct-Coupling O2 Bond Forming a Pathway in Cobalt Oxide Water Oxidation Catalysts. J. Phys. Chem. Lett. 2011, 2 (17), 2200-2204.

(12) Zhang, M.; de Respinis, M.; Frei, H. Time-Resolved Observations of Water Oxidation Intermediates on a Cobalt Oxide Nanoparticle Catalyst. Nat. Chem. 2014, 6 (4), 362-367.

(13) Costentin, C.; Nocera, D. G. Self-Healing Catalysis in Water. Proc. Natl. Acad. Sci. 2017, 114 (51), 13380-13384.

(14) Surendranath, Y.; Kanan, M. W.; Nocera, D. G. Mechanistic Studies of the Oxygen Evolution Reaction by a Cobalt-Phosphate Catalyst at Neutral PH. J. Am. Chem. Soc. 2o1o, 132 (46), 16501-16509.

(15) Friebel, D.; Bajdich, M.; Yeo, B. S.; Louie, M. W.; Miller, D. J.; Casalongue, H. S.; Mbuga, F.; Weng, T.-C.; Nordlund, D.; Sokaras, D.; Alonso-Mori, R.; Bell, A. T.; Nilsson, A. On the Chemical State of Co Oxide Electrocatalysts during Alkaline Water Splitting. Phys. Chem. Chem. Phys. 2o13, 15 (40), 1746o-17467.

(16) Guo, B.; Li, T.; Hu, H. Anodic Deposition of CoOOH Films with Excellent Performance for Electrochemical Capacitors. J. Appl. Electrochem. 2016, 46 (3), 403-421.

(17) Morales-Guio, C. G.; Liardet, L.; Hu, X. Oxidatively Electrodeposited Thin-Film Transition Metal (Oxy)Hydroxides as Oxygen Evolution Catalysts. J. Am. Chem. Soc. 2016, 138 (28), 89468957.

(18) Yeo, B. S.; Bell, A. T. Enhanced Activity of Gold-Supported Cobalt Oxide for the Electrochemical Evolution of Oxygen. J. Am. Chem. Soc. 2011, 133 (14), 5587-5593.

(19) Jung, S.; McCrory, C. C. L.; Ferrer, I. M.; Peters, J. C.; Jaramillo, T. F. Benchmarking Nanoparticulate Metal Oxide Electrocatalysts for the Alkaline Water Oxidation Reaction. J. Mater. Chem. A 2016, 4 (8), 3068-3076.

(20) Wei, C.; Rao, R. R.; Peng, J.; Huang, B.; Stephens, I. E. L.; Risch, M.; Xu, Z. J.; Shao-Horn, Y. Recommended Practices and Benchmark Activity for Hydrogen and Oxygen Electrocatalysis in Water Splitting and Fuel Cells. Adv. Mater. 2019, 31 (31), 1806296.

(21) Biesinger, M. C.; Payne, B. P.; Grosvenor, A. P.; Lau, L. W. M.; Gerson, A. R.; Smart, R. St. C. Resolving Surface Chemical States in XPS Analysis of First Row Transition Metals, Oxides and Hydroxides: Cr, Mn, Fe, Co and Ni. Appl. Surf. Sci. 2011, 257 (7), 2717-2730.

(22) Yang, J.; Liu, H.; Martens, W. N.; Frost, R. L. Synthesis and Characterization of Cobalt Hydroxide, Cobalt Oxyhydroxide, and Cobalt Oxide Nanodiscs. J. Phys. Chem. C 2010, 114 (1), 111-119.

(23) Sathiya, M.; Rousse, G.; Ramesha, K.; Laisa, C. P.; Vezin, H.; Sougrati, M. T.; Doublet, M.-L.; Foix, D.; Gonbeau, D.; Walker, W.; Prakash, A. S.; Ben Hassine, M.; Dupont, L.; Tarascon, J.-M. Reversible Anionic Redox Chemistry in High-Capacity LayeredOxide Electrodes. Nat. Mater. 2013, 12 (9), 827-835.

(24) Sathiya, M.; Abakumov, A. M.; Foix, D.; Rousse, G.; Ramesha, K.; Saubanère, M.; Doublet, M. L.; Vezin, H.; Laisa, C. P.; Prakash, A. S.; Gonbeau, D.; VanTendeloo, G.; Tarascon, J.-M. Origin of Voltage Decay in High-Capacity Layered Oxide Electrodes. Nat. Mater. 2015, 14 (2), 230-238.

(25) Burke, M. S.; Kast, M. G.; Trotochaud, L.; Smith, A. M.; Boettcher, S. W. Cobalt-Iron (Oxy)Hydroxide Oxygen Evolution Electrocatalysts: The Role of Structure and Composition on Activity, Stability, and Mechanism. J. Am. Chem. Soc. 2015, 137 (10), $3638-3648$. 
(26) Koza, J. A.; He, Z.; Miller, A. S.; Switzer, J. A. Electrodeposition of Crystalline $\mathrm{CO}_{3} \mathrm{O}_{4}-\mathrm{A}$ Catalyst for the Oxygen Evolution Reaction. Chem. Mater. 2012, 24 (18), 3567-3573.

(27) Smith, R. D. L.; Prévot, M. S.; Fagan, R. D.; Trudel, S.; Berlinguette, C. P. Water Oxidation Catalysis: Electrocatalytic Response to Metal Stoichiometry in Amorphous Metal Oxide Films Containing Iron, Cobalt, and Nickel. J. Am. Chem. Soc. 2013, 135 (31), 11580-11586.

(28) Burke, L. D.; Lyons, M. E.; Murphy, O. J. Formation of Hydrous Oxide Films on Cobalt under Potential Cycling Conditions. J. Electroanal. Chem. Interfacial Electrochem. 1982, 132, 247-261.

(29) Doyle, R. L.; Godwin, I. J.; Brandon, M. P.; Lyons, M. E. G. Redox and Electrochemical Water Splitting Catalytic Properties of Hydrated Metal Oxide Modified Electrodes. Phys. Chem. Chem. Phys. 2013, 15 (33), 13737-13783.

(30) Amin, H. M. A.; Baltruschat, H. How Many Surface Atoms in $\mathrm{Co}_{3} \mathrm{O}_{4}$ Take Part in Oxygen Evolution? Isotope Labeling Together with Differential Electrochemical Mass Spectrometry. Phys. Chem. Chem. Phys. 2017, 19 (37), 25527-25536.

(31) Zhou, J.; Wang, Y.; Su, X.; Gu, S.; Liu, R.; Huang, Y.; Yan, S.; Li, J.; Zhang, S. Electrochemically Accessing Ultrathin Co (Oxy)-Hydroxide Nanosheets and Operando Identifying Their Active Phase for the Oxygen Evolution Reaction. Energy Environ. Sci. 2019, 12 (2), 739-746.

(32) Liu, Y.-C.; Koza, J. A.; Switzer, J. A. Conversion of Electrodeposited $\mathrm{Co}(\mathrm{OH})_{2}$ to $\mathrm{CoOOH}$ and $\mathrm{CO}_{3} \mathrm{O}_{4}$, and Comparison of Their Catalytic Activity for the Oxygen Evolution Reaction. Electrochimica Acta 2014, 140, 359-365.

(33) Koza, J. A.; Hull, C. M.; Liu, Y.-C.; Switzer, J. A. Deposition of $\beta-\mathrm{Co}(\mathrm{OH})_{2}$ Films by Electrochemical Reduction of Tris(Ethylenediamine)Cobalt(III) in Alkaline Solution. Chem. Mater. 2013, 25 (9), 1922-1926.

(34) Pasquini, C.; D’Amario, L.; Zaharieva, I.; Dau, H. Operando Raman Spectroscopy Tracks Oxidation-State Changes in an Amorphous Co Oxide Material for Electrocatalysis of the Oxygen Evolution Reaction. J. Chem. Phys. 2020, 152 (19), 194202.

(35) Chen, Z.; Cai, L.; Yang, X.; Kronawitter, C.; Guo, L.; Shen, S.; Koel, B. E. Reversible Structural Evolution of NiCoOxHy during the Oxygen Evolution Reaction and Identification of the Catalytically Active Phase. ACS Catal. 2018, 8 (2), 1238-1247.

(36) Kornienko, N.; Heidary, N.; Cibin, G.; Reisner, E. Catalysis by Design: Development of a Bifunctional Water Splitting Catalyst through an Operando Measurement Directed Optimization Cycle. Chem. Sci. 2018, 9 (24), 5322-5333.

(37) Strickler, A. L.; Escudero-Escribano, M.; Jaramillo, T. F. Core-Shell Au@Metal-Oxide Nanoparticle Electrocatalysts for Enhanced Oxygen Evolution. Nano Lett. 2o17, 17 (10), 6040-6046.

(38) Frydendal, R.; Busch, M.; Halck, N. B.; Paoli, E. A.; Krtil, P.; Chorkendorff, I.; Rossmeisl, J. Enhancing Activity for the Oxygen Evolution Reaction: The Beneficial Interaction of Gold with Manganese and Cobalt Oxides. ChemCatChem 2015, 7 (1), 149-154.

(39) Sayeed, M. A.; Herd, T.; O’Mullane, A. P. Direct Electrochemical Formation of Nanostructured Amorphous $\mathrm{Co}(\mathrm{OH})_{2}$ on Gold Electrodes with Enhanced Activity for the Oxygen Evolution Reaction. J. Mater. Chem. A 2016, 4 (3), 991-999.

(40) Merrill, M.; Worsley, M.; Wittstock, A.; Biener, J.; Stadermann, M. Determination of the "NiOOH" Charge and Discharge Mechanisms at Ideal Activity. J. Electroanal. Chem. 2014, 717-718, 177-188.

(41) Diaz-Morales, O.; Ferrus-Suspedra, D.; Koper, M. T. M. The Importance of Nickel Oxyhydroxide Deprotonation on Its Activity towards Electrochemical Water Oxidation. Chem. Sci. 2016, 7 (4), 2639-2645.

(42) Lee, S.; Banjac, K.; Lingenfelder, M.; Hu, X. Oxygen Isotope Labeling Experiments Reveal Different Reaction Sites for the Oxygen Evolution Reaction on Nickel and Nickel Iron Oxides. Angew. Chem. Int. Ed. 2019, 58 (30), 10295-10299.
(43) Smith, R. D. L.; Berlinguette, C. P. Accounting for the Dynamic Oxidative Behavior of Nickel Anodes. J. Am. Chem. Soc. 2016, 138 (5), 1561-1567.

(44) Trześniewski, B. J.; Diaz-Morales, O.; Vermaas, D. A.; Longo, A.; Bras, W.; Koper, M. T. M.; Smith, W. A. In Situ Observation of Active Oxygen Species in Fe-Containing Ni-Based Oxygen Evolution Catalysts: The Effect of PH on Electrochemical Activity. J. Am. Chem. Soc. 2015, 137 (48), 15112-15121.

(45) Barraclough, C. G.; Lawrance, G. A.; Lay, P. A. Characterization of Binuclear .Mu.-Peroxo and .Mu.-Superoxo Cobalt(III) Amine Complexes from Raman Spectroscopy. Inorg. Chem. 1978, 17 (12), 3317-3322.

(46) Shibahara, T.; Mori, M. Raman and Infrared Spectra of $\mu$ O2 Dicobalt(III) Complexes. Bull. Chem. Soc. Jpn. 1978, 51 (5), 1374-1379.

(47) Wang, H.-Y.; Hung, S.-F.; Hsu, Y.-Y.; Zhang, L.; Miao, J.; Chan, T.-S.; Xiong, Q.; Liu, B. In Situ Spectroscopic Identification of $\mu$-OO Bridging on Spinel $\mathrm{Co}_{3} \mathrm{O}_{4}$ Water Oxidation Electrocatalyst. J. Phys. Chem. Lett. 2016, 7 (23), 4847-4853.

(48) Masikhwa, T. M.; Madito, M. J.; Momodu, D.; Bello, A.; Dangbegnon, J. K.; Manyala, N. High Electrochemical Performance of Hybrid Cobalt Oxyhydroxide/Nickel Foam Graphene. J. Colloid Interface Sci. 2016, 484, 77-85.

(49) Gerken, J. B.; McAlpin, J. G.; Chen, J. Y. C.; Rigsby, M. L.; Casey, W. H.; Britt, R. D.; Stahl, S. S. Electrochemical Water Oxidation with Cobalt-Based Electrocatalysts from $\mathrm{PH}$ o-14: The Thermodynamic Basis for Catalyst Structure, Stability, and Activity. J. Am. Chem. Soc. 2011, 133 (36), 14431-14442.

(5o) Bockris, J. O.; Otagawa, T. Mechanism of Oxygen Evolution on Perovskites. J. Phys. Chem. 1983, 87 (15), 2960-2971.

(51) Elizier Gileadi. Multi-Step Electrode Reactions. In Electrode Kinetics for Chemists, Chemical Engineers, and Material Scientists.; VCH Publishers, Inc.: New York, 1993; pp 127-184.

(52) Görlin, M.; Ferreira de Araújo, J.; Schmies, H.; Bernsmeier, D.; Dresp, S.; Gliech, M.; Jusys, Z.; Chernev, P.; Kraehnert, R.; Dau, H.; Strasser, P. Tracking Catalyst Redox States and Reaction Dynamics in Ni-Fe Oxyhydroxide Oxygen Evolution Reaction Electrocatalysts: The Role of Catalyst Support and Electrolyte PH. J. Am. Chem. Soc. 2017, 139 (5), 2070-2082.

(53) Burke, L. D.; Lyons, M. E.; Whelan, D. P. Influence of Ph on the Reduction of Thick Anodic Oxide Films on Gold. J. Electroanal. Chem. Interfacial Electrochem. 1982, 139 (1), 131-142.

(54) Wildi, C.; Cabello, G.; Zoloff Michoff, M. E.; Vélez, P.; Leiva, E. P. M.; Calvente, J. J.; Andreu, R.; Cuesta, A. Super-Nernstian Shifts of Interfacial Proton-Coupled Electron Transfers: Origin and Effect of Noncovalent Interactions. J. Phys. Chem. C 2016, 120 (29), 15586-15592.

(55) Lyons, M. E. G.; Cakara, A.; O’Brien, P.; Godwin, I.; Doyle, R. L. Redox, PH Sensing and Electrolytic Water Splitting Properties of Electrochemically Generated Nickel Hydroxide Thin Films in Aqueous Alkaline Solution. Int J Electrochem Sci 2012, 7, 28.

(56) Lyons, M. E. G.; Brandon, M. P. A Comparative Study of the Oxygen Evolution Reaction on Oxidised Nickel, Cobalt and Iron Electrodes in Base. J. Electroanal. Chem. 2010, 641 (1), 119-130.

(57) Burke, L. D.; Lyons, M. E. G. The Formation and Stability of Hydrous Oxide Films on Iron under Potential Cycling Conditions in Aqueous Solution at High PH. J. Electroanal. Chem. Interfacial Electrochem. 1986, 198 (2), 347-368.

(58) Burke, L. D.; Whelan, D. P. A Voltammetric Investigation of the Charge Storage Reactions of Hydrous Iridium Oxide Layers. J. Electroanal. Chem. Interfacial Electrochem. 1984, 162 (1), 121-141.

(59) Lyons, M. E. G.; Doyle, R. L.; Brandon, M. P. Redox Switching and Oxygen Evolution at Oxidized Metal and Metal Oxide Electrodes: Iron in Base. Phys. Chem. Chem. Phys. 2011, 13 (48), 21530-21551.

(6o) McAlpin, J. G.; Surendranath, Y.; Dincă, M.; Stich, T. A.; Stoian, S. A.; Casey, W. H.; Nocera, D. G.; Britt, R. D. EPR Evidence 
for Co(IV) Species Produced During Water Oxidation at Neutral PH. J. Am. Chem. Soc. 2010, 132 (20), 6882-6883.

(61) Kanan, M. W.; Yano, J.; Surendranath, Y.; Dincă, M.; Yachandra, V. K.; Nocera, D. G. Structure and Valency of a Cobalt-Phosphate Water Oxidation Catalyst Determined by in Situ X-Ray Spectroscopy. J. Am. Chem. Soc. 2010, 132 (39), 13692-13701.

(62) Tse, E. C. M.; Hoang, T. T. H.; Varnell, J. A.; Gewirth, A. A. Observation of an Inverse Kinetic Isotope Effect in Oxygen Evolution Electrochemistry. ACS Catal. 2016, 6 (9), 5706-5714.

(63) Grimaud, A.; Diaz-Morales, O.; Han, B.; Hong, W. T.; Lee, Y.-L.; Giordano, L.; Stoerzinger, K. A.; Koper, M. T. M.; ShaoHorn, Y. Activating Lattice Oxygen Redox Reactions in Metal Oxides to Catalyse Oxygen Evolution. Nat. Chem. 2017, 9 (5), 457465 .

(64) Diaz-Morales, O.; Calle-Vallejo, F.; Munck, C. de; Koper, M. T. M. Electrochemical Water Splitting by Gold: Evidence for an Oxide Decomposition Mechanism. Chem. Sci. 2013, 4 (6), 2334-2343.

(65) Li, X.; Wang, H.; Cui, Z.; Li, Y.; Xin, S.; Zhou, J.; Long, Y.; Jin, C.; Goodenough, J. B. Exceptional Oxygen Evolution Reactivities on $\mathrm{CaCoO}_{3}$ and $\mathrm{SrCoO}_{3}$. Sci. Adv. 2019, 5 (8), eaav6262.

(66) Sathiya, M.; Ramesha, K.; Rousse, G.; Foix, D.; Gonbeau, D.; Prakash, A. S.; Doublet, M. L.; Hemalatha, K.; Tarascon, J.-M. High Performance Li2Ru1-YMnyO3 $(0.2 \leq \mathrm{y} \leq 0.8)$ Cathode Materials for Rechargeable Lithium-Ion Batteries: Their Understanding. Chem. Mater. 2013, 25 (7), 1121-1131.

(67) Jakubek, T.; Kaspera, W.; Legutko, P.; Stelmachowski, P.; Kotarba, A. How to Efficiently Promote Transition Metal Oxides by Alkali Towards Catalytic Soot Oxidation. Top. Catal. 2016, 59 (10), 1083-1089.

(68) Grimaud, A.; Hong, W. T.; Shao-Horn, Y.; Tarascon, J.-M. Anionic Redox Processes for Electrochemical Devices. Nat. Mater. 2016, 15, 121-126.

(69) Saubanère, M.; McCalla, E.; Tarascon, J.-M.; Doublet, M.L. The Intriguing Question of Anionic Redox in High-Energy Density Cathodes for Li-Ion Batteries. Energy Environ. Sci. 2016, 9 (3), 984-991.

(7o) Zhang, S.; Gu, S.; Wang, Y.; Liang, C.; Yu, Y.; Han, L.; Zheng, S.; Zhang, N.; Liu, X.; Zhou, J.; Li, J. Spontaneous Delithiation under Operando Condition Triggers Formation of an Amorphous Active Layer in Spinel Cobalt Oxides Electrocatalyst toward Oxygen Evolution. ACS Catal. 2019, 9 (8), 7389-7397.

(71) Koroidov, S.; Anderlund, M. F.; Styring, S.; Thapper, A.; Messinger, J. First Turnover Analysis of Water-Oxidation Catalyzed by Co-Oxide Nanoparticles. Energy Environ. Sci. 2015, 8 (8), 2492-2503.

(72) Mattioli, G.; Giannozzi, P.; Amore Bonapasta, A.; Guidoni, L. Reaction Pathways for Oxygen Evolution Promoted by Cobalt Catalyst. J. Am. Chem. Soc. 2o13, 135 (41), 15353-15363.

(73) Li, X.; Siegbahn, P. E. M. Water Oxidation Mechanism for Synthetic Co-Oxides with Small Nuclearity. J. Am. Chem. Soc. 2013, 135 (37), 13804-13813.

(74) Bajdich, M.; García-Mota, M.; Vojvodic, A.; Nørskov, J. K.; Bell, A. T. Theoretical Investigation of the Activity of Cobalt Oxides for the Electrochemical Oxidation of Water. J. Am. Chem. Soc. 2013, 135 (36), 13521-13530.

(75) Wasylenko, D. J.; Ganesamoorthy, C.; Henderson, M. A.; Koivisto, B. D.; Osthoff, H. D.; Berlinguette, C. P. Electronic Mod- ification of the $[\mathrm{RuII}(\mathrm{Tpy})(\mathrm{Bpy})(\mathrm{OH} 2)]_{2}+$ Scaffold: Effects on Catalytic Water Oxidation. J. Am. Chem. Soc. 2010, 132 (45), 1609416106.

(76) Concepcion, J. J.; Jurss, J. W.; Templeton, J. L.; Meyer, T. J. One Site Is Enough. Catalytic Water Oxidation by $[\mathrm{Ru}(\mathrm{Tpy})(\mathrm{Bpm})(\mathrm{OH} 2)]_{2+}$ and $\left[\mathrm{Ru}(\mathrm{Tpy})(\mathrm{Bpz})\left(\mathrm{OH}_{2}\right)\right]_{2+}$. J. Am. Chem. Soc. 2008, 130 (49), 16462-16463.

(77) Plaisance, C. P.; van Santen, R. A. Structure Sensitivity of the Oxygen Evolution Reaction Catalyzed by Cobalt(II,III) Oxide. J. Am. Chem. Soc. 2015, 137 (46), 1466o-14672.

(78) Wang, H.-Y.; Hung, S.-F.; Chen, H.-Y.; Chan, T.-S.; Chen, H. M.; Liu, B. In Operando Identification of Geometrical-Site-Dependent Water Oxidation Activity of Spinel $\mathrm{Co}_{3} \mathrm{O}_{4}$. J. Am. Chem. Soc. 2016, 138 (1), 36-39.

(79) Favaro, M.; Yang, J.; Nappini, S.; Magnano, E.; Toma, F. M.; Crumlin, E. J.; Yano, J.; Sharp, I. D. Understanding the Oxygen Evolution Reaction Mechanism on CoOx Using Operando Ambient-Pressure X-Ray Photoelectron Spectroscopy. J. Am. Chem. Soc. 2017, 139 (26), 8960-8970.

(8o) Bergmann, A.; Martinez-Moreno, E.; Teschner, D.; Chernev, P.; Gliech, M.; de Araújo, J. F.; Reier, T.; Dau, H.; Strasser, P. Reversible Amorphization and the Catalytically Active State of Crystalline $\mathrm{Co}_{3} \mathrm{O}_{4}$ during Oxygen Evolution. Nat. Commun. 2015, 6 (1), 8625 .

(81) Trotochaud, L.; Young, S. L.; Ranney, J. K.; Boettcher, S. W. Nickel-Iron Oxyhydroxide Oxygen-Evolution Electrocatalysts: The Role of Intentional and Incidental Iron Incorporation. J. Am. Chem. Soc. 2014, 136 (18), 6744-6753.

(82) McCrory, C. C. L.; Jung, S.; Peters, J. C.; Jaramillo, T. F. Benchmarking Heterogeneous Electrocatalysts for the Oxygen Evolution Reaction. J. Am. Chem. Soc. 2013, 135 (45), 16977-16987.

(83) Chakthranont, P.; Kibsgaard, J.; Gallo, A.; Park, J.; Mitani, M.; Sokaras, D.; Kroll, T.; Sinclair, R.; Mogensen, M. B.; Jaramillo, T. F. Effects of Gold Substrates on the Intrinsic and Extrinsic Activity of High-Loading Nickel-Based Oxyhydroxide Oxygen Evolution Catalysts. ACS Catal. 2017, 7 (8), 5399-5409.

(84) T. Hong, W.; Risch, M.; A. Stoerzinger, K.; Grimaud, A.; Suntivich, J.; Shao-Horn, Y. Toward the Rational Design of NonPrecious Transition Metal Oxides for Oxygen Electrocatalysis. Energy Environ. Sci. 2015, 8 (5), 1404-1427.

(85) Hoogvliet, J. C.; Dijksma, M.; Kamp, B.; van Bennekom, W. P. Electrochemical Pretreatment of Polycrystalline Gold Electrodes To Produce a Reproducible Surface Roughness for Self-Assembly: A Study in Phosphate Buffer PH 7.4. Anal. Chem. 2ooo, 72 (9), 2016-2021.

(86) Oesch, U.; Janata, J. Electrochemical Study of Gold Electrodes with Anodic Oxide Films-I. Formation and Reduction Behaviour of Anodic Oxides on Gold. Electrochimica Acta 1983, 28 (9), 1237-1246. 
Insert Table of Contents artwork here

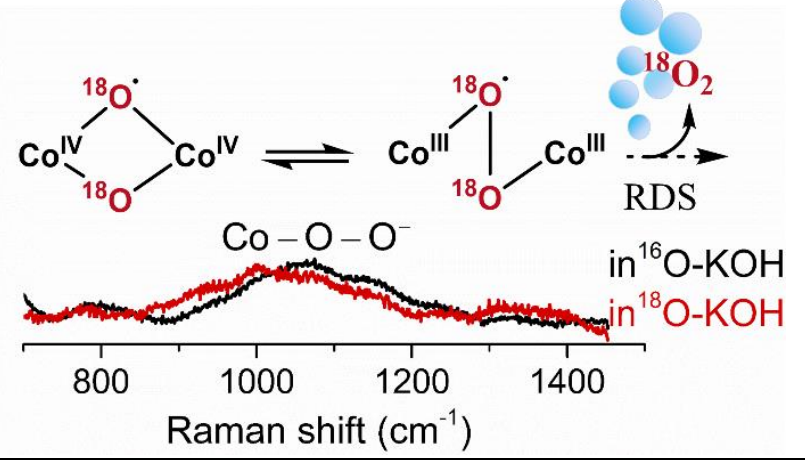

